\title{
Barriers to Migration in a System of Cities*
}

\author{
Nathan Seegert \\ Department of Finance, University of Utah
}

November 27, 2014

\begin{abstract}
This paper creates a model where heterogeneous cities, in production and quality of life amenities, are created under different policy regimes that create barriers to migration. When policies are set by local governments, too many cites are created and these are biased toward providing high quality of life amenities. If instead, there are no policies that limit migration, too few cities are created and these are biased toward high production amenity cities. In contrast, this paper demonstrates a market mechanism (implementable through local zoning regulations) that provides the incentives for individuals to create and move across cities efficiently, despite the lack of coordination across cities. These results demonstrate the importance of accounting for barriers to migration and agglomeration benefits when estimating production and quality of life amenity levels. Otherwise, if there is path dependence in city growth, the estimated amenity levels will be biased toward cities with amenities important in previous centuries.
\end{abstract}

\section{Keywords: Land use, urban economics, mobility, city growth JEL Classification: R52, H73, R12, J61}

${ }^{*}$ I am grateful to Luis Rayo, Stephen Salant, participants at Urban Economics Association meetings and the Annual North American meetings of the Regional Science Association International. 


\section{Introduction}

The mobility of individuals in a country affects whether production and population are concentrated in a few cities or dispersed among many cities. These distributions affect the economies and diseconomies of scale inherent in cities, which fundamentally affects the economic growth in a country. An efficient distribution balances allocating more people in fewer cities, incurring the costs from decreasing returns to scale within each city, and allocating fewer people across more cities, incurring the costs from decreasing returns to scale in the distribution of city amenities in production and quality of life.

This paper demonstrates intervention from a central government is unnecessary to produce the efficient concentration of production and people across cities, similar to Knight's 1924 response to Pigou (1920). ${ }^{1}$ Specifically, if individuals that creates a city, or a revenue maximizing city government, is able to charge people a fee to work and live in their city then the concentration of production and people across cities will be efficient. In practice, this suggests zoning laws may be efficiently set at the local level if they act as a fee charged to individuals moving to the city. Conceptually, zoning laws may act as a fee to individuals moving into a city because zoning laws artificially increase the cost of housing by limiting its supply.

Most restrictions on urban growth, such as zoning laws, are determined at the local level. If cities maximize the per resident benefit within the city and cities are heterogeneous then the resulting population distribution will be inefficient from the national perspective (Albouy and Seegert, 2011). In this case, cities act as exclusive clubs that monopolize heterogeneous production and quality of life amenities. However, a system of cities with no barriers to migration will also be inefficient. In this case, cities with the highest amenity levels will become overcrowded because individuals do not internalize the crowding externalities they impose on other city residents (Arnott and Stiglitz, 1979; Anas, 1992; Henderson, 1986; Helsley and Strange, 1994). This case is analogous to the example with two heterogeneous roads Pigou (1920) uses to demonstrate the role for government intervention to ensure the distribution of cars is efficient, specifically "Pigouvian" taxes.

Efficiency requires not only that production and people are distributed efficiently across

\footnotetext{
${ }^{1}$ Knight (1924) responds to Pigou (1920) by demonstrating that if a revenue maximizing toll setter exists on the fast and congestible road then the toll set in equilibrium would be the efficient toll, which is equal to the "Pigouvian" tax. For a larger discussion on the generality of Knight's result see Salant and Seegert (2014).
} 
a set of cities but also that the efficient set of cities is created. ${ }^{2}$ Cities differ in the production and quality of life amenities they provide (Desmet and Rossi-Hansberg, 2013; Roback, 1982; Albouy, 2012; Saiz, 2010; Davies and Weinstein, 2002). In addition, which cities are created is not random (Bleakley and Lin, 2012) and depends on the incentives that exist for individuals to create new cities (Seegert, 2011).

This paper shows excessive mobility distorts city creation toward cities with production amenities while excessive restrictions distort city creation toward cities with quality of life amenities. These distortion exists because population has a positive spillover for cities with high production amenities and a negative spillover for cities with high quality of life amenities. However, if individuals are charged the revenue maximizing fee to live in work in a city then the decentralized individuals that set the fee will endogenously create the efficient set of cities. $^{3}$ Surprisingly, the revenue incentives cause individuals that create cities to correctly value these amenities.

The efficient set of cities to create, and encourage growth in, depends critically on the amenity levels that exist in each city. Intuitively, variation in the differences in wages and local prices across cities can be used to estimate amenity levels (Rosen, 1979; Roback, 1982; Albouy, 2009). However, wages may be high in a city because of production amenities or because of larger agglomeration benefits, due to more population. If the agglomeration benefits are not taken into account the level of production amenities in larger cities will be biased upwards. This is important because cities may have large populations if they initially had large production amenities, for example if the city was near a rapids in a river that needed to be portaged (Bleakley and Lin, 2012), and there is some amount of path dependence in city growth. Therefore, to estimate the current production amenities a full model of urban growth that takes into account agglomeration is necessary.

Similarly, rents may be high because of quality of life amenities or restrictions on density, whether natural or imposed. If density is ignored quality of life amenities in cities with density restrictions will be biased upwards. To estimate these amenity levels, explicitly accounting for agglomeration and density, a series of moment conditions are derived from the

\footnotetext{
${ }^{2}$ Fujita and Thisse (2013) provides a detailed overview of the fundamental trade off in urban economics between agglomeration economies and congestion. Albouy and Seegert (2011) demonstrate, with the use of a calibrated model, that this tradeoff depends critically on the heterogeneity of all of the cities in the system of cities.

${ }^{3}$ The timing of city creation has been studied most recently in dynamic models by Seegert (2011) and Henderson and Venables (2009), and is not considered here. The importance of city creation is discussed by Abdel-Rahman and Anas (2004) and demonstrated in work by Henderson (1986); Cuberes (2004); Helsley and Strange (1994).
} 
model. In addition, this estimation allows for nonlinear effect, for example rents within a city do not linearly increase with population. In some contexts nonlinearities are unimportant, for example if the data lack extreme outliers or the estimates for these outliers are unimportant. In contrast, the distribution of cities has large outliers and the estimates for these outliers are of extreme importance for efficiency.

Section 2 discuss the related literature. Section 3 defines the model, provides a microfounded example, and characterizes the four policies that create barriers to migration analyzed in this paper. Section 4 solves for and compares the distribution of population across cities in these four cases. The estimation of the amenity levels is described and reported in section 5 .

\section{Related Literature}

Much of the current urban research is built upon Henderson's 1974 seminal paper on city sizes and types. Henderson's paper provided a tractable model that incorporated a tradeoff between agglomeration and congestion (Arnott and Stiglitz, 1979; Fujita et al., 1978; Tolley, 1974). This model has been extended to systems of cities by Henderson (1986), Ioannides (1979), Henderson and Ioannides (1981) and Capozza and Helsley (1990). In these models new cities are created by land developers that cap city size. Each city's population is capped at the population that maximizes the per resident utility. Cities accommodate additional population only when the total population can not be divided into cities with their per resident utility-maximizing populations. New cities are created as soon as the total population is large enough to populate all cities with their utility-maximizing populations. ${ }^{4} \mathrm{~A}$ result from these models is that cities will be created with time intervals that become shorter as total population increases.

Anas (1992) compared the city creation and growth under laissez-faire and planned systems. A laissez-faire system creates cities at a slower rate than a system of cities organized by a planner. In addition, the laissez-faire system of cities is characterized by "panicmigrations," as Anas stated in his 1992 paper, where large populations in existing cities instantaneously move to form a new city. These cycles of booms and busts are caused by a coordination failure amongst individuals who are unwilling to create a new city unilaterally until current cities are grossly-overpopulated. Given these patterns of laissez-faire city

\footnotetext{
${ }^{4}$ This constraint on creating a new city is an equilibrium stability condition.
} 
creation this model requires periodic government intervention to improve welfare.

To avoid government intervention, "large agents" such as land developers could be modeled to create cities. Helsley and Strange in their 1994 paper introduced the idea that durable capital could be used by land developers to solve the coordination problem amongst individuals. Durable capital has been used in subsequent models to solve this coordination problem, for example Cuberes (2005), Venables (2005), and Henderson and Venables (2009).

Despite the tractability of using land developers and durable capital Krugman in his 1996 paper emphasizes the desirability of creating urban models solely as a result of individuals' choices. Following this emphasis Seegert's 2011 paper creates a model of forward-looking individuals that tradeoff benefits that exist in established cities with opportunities that exist in new cities. When aggregated these decisions characterize the dynamic growth of cities. Dynamic growth in Seegert (2011) allows for rushes of migration, sequential growth where some cities grow fast enough to become larger than other cities, and cities that continue to grow through time.

In the following model individuals create cities and move across them in a two stage game. The dynamic choices of individuals aggregate to characterize which cities are created and the population that resides within them.

\section{Model}

\subsection{Setup}

This section develops a general model, used to characterize the population allocation and set of cities created with different types of polices that act as barriers to migration (propositions 1-3), and a model with added structure used to estimate amenity levels across cities. The model consists of a two stage game. In the first stage individuals sequentially decide whether to create a city, with the constraint that they must live in the city they create. ${ }^{5}$ In the second stage, individuals that did not create a city sequentially decide which established city to move to, subject to the barriers of migration that exist.

I consider four institutional arrangements of barriers to migration that are characterized by either a planner or decentralized individuals setting one of four possible policies. The first

\footnotetext{
${ }^{5}$ This dynamic game setup is similar to Helsley and Strange (1994) where city developers with sunk investments on public goods solve a coordination problem. For a dynamic model of city growth without large agents see Seegert (2011).
} 
case considers a planner that sets city-specific taxes, $\tau_{j}$, that act as barriers to migration by increasing the cost of moving to a given city $j$. This case provides the efficient benchmark for the model. The second case gives individuals that create a city exclusionary power allowing them to decide the population limit of a city, $\hat{N}_{j}$, similar to local governments or clubs. The third case consists of individuals without the ability to limit migration, this provides the free mobility allocation. Finally, an individual that creates city $j$ is allowed to set a city-specific fee $f_{j}$ that each individual must pay to live within city $j$. All individuals have complete and perfect information. Specifically, each individual knows the barriers of migration that exist and all of the prior decisions made by other individuals. With this information each individual makes his decisions to maximize the benefit he receives.

There are $N$ individuals, assumed to be a real number, with homogenous preferences. ${ }^{6}$ These individuals make their decisions sequentially according to a randomly assigned order. For cases 2-4, individuals in the first stage decide which city, if any, to create from an exogenous and finite set of cites $\mathcal{J}$. City sites differ in the level of amenities to production, $A_{j}>0$, and quality of life, $Q_{j}$, they provide. These amenities affect the per-capita benefit each city produces,

$$
b_{j}\left(N_{j}\right)=A_{j} N_{j}^{\alpha}+Q_{j} N^{-\gamma}-B N_{j}^{\beta},
$$

that also depends on the city's population $N_{j}$, where $B>0, \gamma>0$, and $\alpha \in(0,0.5)$.

In the second stage, individuals decide to move to one of the $\mathcal{K} \subset \mathcal{J}$ cities created in the first stage or the hinterland, indexed as city site 0 . Each individual in city $j$ receives the benefit $b_{j}\left(N_{j}\right)$ but must pay any taxes or fees that may exist. The average benefit is subject to a tradeoff between agglomeration economies (represented by $A_{j} N_{j}^{\alpha}$ ) and urban costs (represented by $B N_{j}^{\beta}$ ). The average benefit in each city is continuously differentiable, concave, and is a strictly increasing and then strictly decreasing, but at a slower rate, function. In contrast, the hinterland produces a constant level of benefit independent of how many individuals live there $b_{0}\left(N_{0}\right)=\bar{y}$. Figure 1 provides an example of the average and marginal benefits of a city with respect to population. The average and marginal benefit of the hinterland is depicted as the horizontal line in Figure 1. The following example provides a micro-foundation for the tradeoff between agglomeration economies and urban costs.

\footnotetext{
${ }^{6}$ Assuming the number of individuals is a real number abstracts from integer problems.
} 
Figure 1: Average and Marginal Benefit

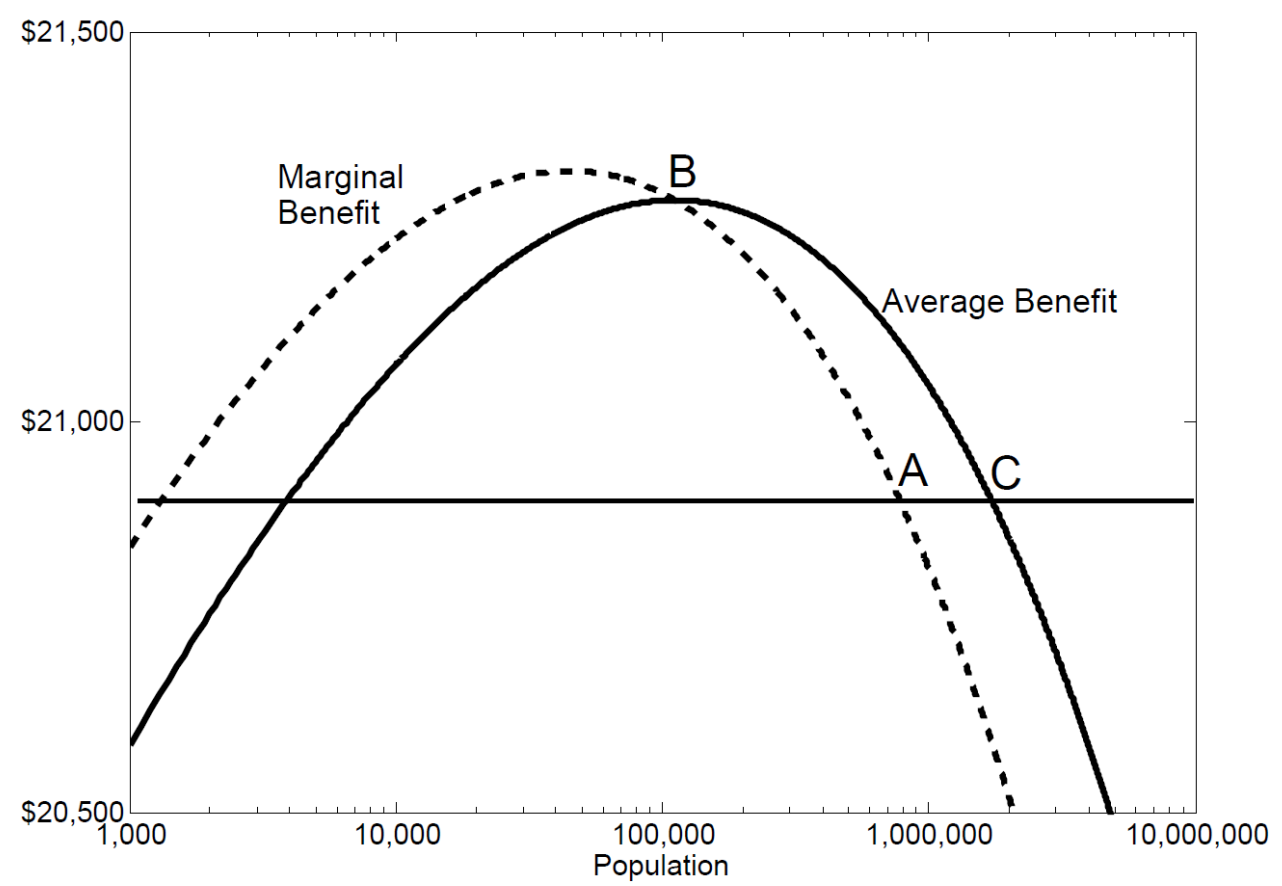

Figure 1 graphs the average benefit given in equation 1 using the calibration from Albouy and Seegert (2011) for context.

\subsection{Example}

This section provides, by way of example, additional structure for the average benefit given in equation (1). Moment conditions derived from this model are used to estimate amenity levels in section 5 .

\section{Spatial Growth: Land Consumption}

Each city expands with population $N_{j}$ from the central business district (CBD) where all production occurs. The city grows radially in three dimensions as a half oblate ellipsoid where the footprint is circular, depicted in Figure 2. A half oblate ellipsoid is a three dimensional analogue of a half ellipse characterized by three semi-principal axes where two of the axes are equal and the third is smaller. The first two semi-principal axes characterize the footprint of the city, $s_{j}^{\max }\left(N_{j}\right)$. The third semi-principal axis characterizes the height $\delta_{j}\left(N_{j}\right)=A_{h_{j}} s_{j}^{\max }\left(N_{j}\right)$, that increases with population according to a housing production 
amenity $A_{h, j}$, which is heterogeneous across cities. The density (the height at any given point on the footprint) is the largest at the center, decreases toward the edge of the city, and increases as the semi-principal axes of the footprint of the city increases. Each individual is assumed to consume one unit of housing such that the population of the city is given by the volume of the half ellipsoid,

$$
N_{j}=\frac{2}{3} \pi \delta_{j} s_{j}^{\max }\left(N_{j}\right)^{2}
$$

Figure 2: City Geography: Half Ellipsoid

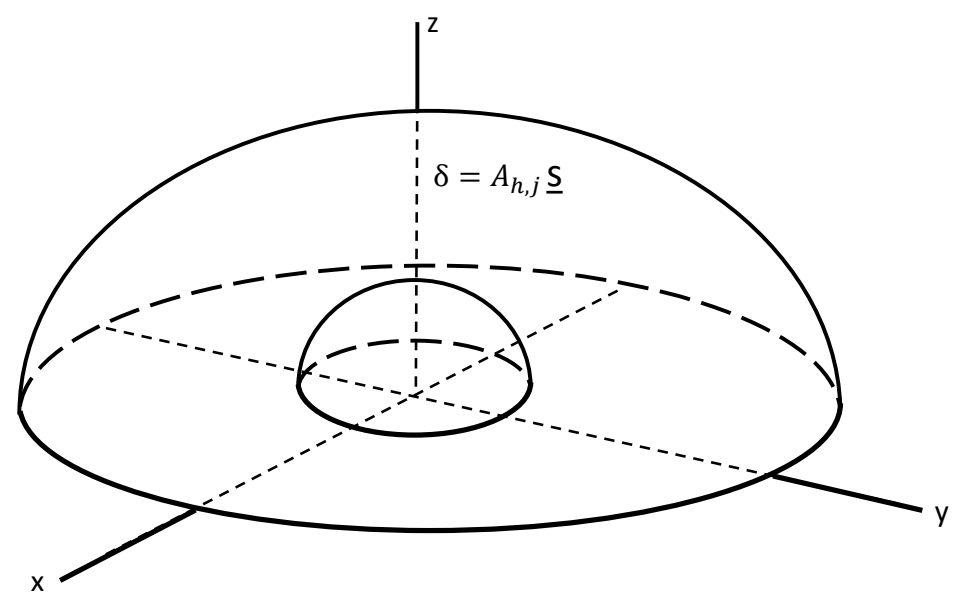

Agglomeration Economies: Aggregate Production

Each individual is endowed with one unit of time. An individual that lives at a distance $s$, characterized by the footprint distance, consumes $c s$ commuting and supplies $1-c s$ labor. Production in cities occurs in two sectors; a tradeable sector, producing the numeraire good $x$, and a housing sector, $h$ (exclusive of land), which is not traded and has a local price $p_{j}$.

The aggregate production in the tradeable sector is given by $F_{x}\left(A_{x, j}, N_{j}\right)=A_{x, j} N_{j}^{\alpha} L\left(N_{j}\right) \eta_{x}$, which is subject to agglomeration economies, $N_{j}^{\alpha}$, and is a function of the production amenities in the tradeable sector, $A_{x, j}$, aggregate labor, $L\left(N_{j}\right)$, and $\eta_{x}$, the fraction of labor working in the tradeable sector. ${ }^{7}$ Similarly, aggregate production in the housing sector is given by $F_{h}\left(A_{h, j}, N_{j}\right)=A_{h, j} N_{j}^{\alpha} L\left(N_{j}\right)\left(1-\eta_{x}\right)$.

Labor is paid its marginal product, $w_{j}=A_{x, j} N_{j}^{\alpha}=p_{j} A_{h, j} N_{j}^{\alpha}$, that is increasing with population in the city. ${ }^{8}$ In equilibrium, the price of housing $p_{j}$ adjusts such that the wage

\footnotetext{
${ }^{7}$ The aggregate labor supply is given by $L_{j}\left(N_{j}\right)=N_{j}\left(1-\tilde{c}_{j} N_{j}^{1 / 3}\right)$ where $\tilde{c}_{j}=(3 / 4)\left(3 /\left(2 \pi A_{h, j}\right)\right)^{1 / 3} c$.

${ }^{8}$ Both sectors experience agglomeration economies that are external to firms but internal to cities, such
} 
is the in both industries. Individuals are willing to work in either industry and the fraction of labor supply in the housing sector is determined by the market-clearing condition for housing, $N_{j}=F_{h}\left(A_{h, j}, N_{j}\right)$, where each individual demands one unit of housing

\section{Urban Costs: Commuting and Rent}

Urban costs are given by the sum of commuting and land rent costs. The aggregate commuting cost in city $j$ is given by $w_{j} \tilde{c}_{j} N_{j}^{4 / 3}$, which increases with population. ${ }^{9}$ Individuals bid up land rents such that the the urban costs are equal within the city, $r(s)+w_{j} c s=$ $w_{j} c s_{j}^{\max }\left(N_{j}\right)$, where land rents at the edge of the city are normalized to zero. Land rents are highest at the center of the city and decrease with distance from the center according to the land rent gradient $r_{j}(s)=w_{j} c\left(s_{j}^{\max }\left(N_{j}\right)-s\right)$. Land rents are paid to individuals who are assumed to own identical and nationally-diversified portfolios of land. ${ }^{10}$

\section{Average Benefit: Individual Utility}

Individuals consume the numeraire traded good, $x$, and housing, $h$. Each individual is assumed to demand one unit of housing with a local price $p_{j}$. Utility of an individual can then be written as $U\left(x, h ; Q_{j}\right)=x+h+Q_{j} N^{-\gamma}$, where $Q_{j}$ is the quality of life amenities city $j$ provides, such as sunshine. Quality of life amenities capture city site specific amenities. For example, the MET opera in New York city is not captured by this quality of life amenity because it is not specific to New York City's location but its population. Presumably, if the population of New York city was moved to Omaha, Nebraska the quality of the opera in Omaha would increase.

Individuals pay for the traded good with the wages and land rent income, $I$, they receive minus the cost of housing and the urban costs they incur, $w_{j}+I=x+p_{j}+w_{j} c s_{j}^{\max }$. The benefit an individual receives by living in city $j$ when the urban costs are written as the average commuting cost plus the average rent is given by,

$$
b_{j}\left(N_{j}\right)=A_{x, j} N_{j}^{\alpha}\left(1-c_{j} N_{j}^{1 / 3}\right)-r_{T, j}+Q_{j} N^{-\gamma}+I+1
$$

that firms exhibit constant returns to scale with respect to labor but cities exhibit increasing returns to scale with respect to population. The zero profit condition for firm $k$ in city $j$ is given by $\Pi_{j, k}=0=$ $A_{x, j} N_{j}^{\alpha} l_{k}-w_{k} l_{k}$.

${ }^{9}$ The cost parameter $c$ can be rearranged such that $\tilde{c}_{j}=(3 / 4)\left(3 /\left(2 \pi A_{h, j}\right)\right)^{1 / 3} c$.

${ }^{10}$ The assumption that land rents are paid back to individuals through lump sum payments is not essential. For more information on the distortions of assumptions on land rent income see Albouy and Seegert (2010). 
where $r_{T, j}$ is the average rent (land inclusive) and $b_{j}\left(N_{j}\right)$ is the average benefit produced within city $j$. The average benefit is increasing and then decreasing in population, with a unique maximum. ${ }^{11}$ The assumptions in the example ensure the average benefit is continuous, twice differentiable, and initially increasing and then decreasing in population-the key assumptions of the model.

\section{Zoning as a Fee To Residents}

consider a city that can limit its housing productivity, $A_{h, j}$, by creating restrictive zoning laws. Intuitively, the rent within the city increases as an effect of the these zoning laws.

The rent gradient within a city is given by a cone centered on the center of the city. Figure 3 depicts two of these rent gradients; one with zoning laws and one without.

Zoning lowers $A_{h, j}$, increases the footprint of city $j\left(s_{j}^{\max }\left(N_{j}\right)=\left(3 N_{j} /\left(2 \pi A_{h, j}\right)^{1 / 3}\right)\right.$, and increases the intercept of the rent gradient $\left(r_{j}(s)=w_{j}\left(s_{j}^{\max }-s\right)\right)$. With zoning restrictions rent at every distance $s$ is a constant $f$ higher, which can be thought of as a fee the city charges people to move into the city.

Zoning, through housing productivity, affects the intercept of the rent gradient, $r_{j}(s)=$ $w_{j} c\left(\left(3 /\left(2 \pi A_{h, j}\right)\right)^{1 / 3} N^{1 / 3}-s\right)$, such that rent at every distance $s$ is a constant $f$ higher with lower housing productivity. The constant shift in rent can be thought of as a fee the city charges people to move into the city.

Figure 3: Rent Gradients With Different Zoning Laws

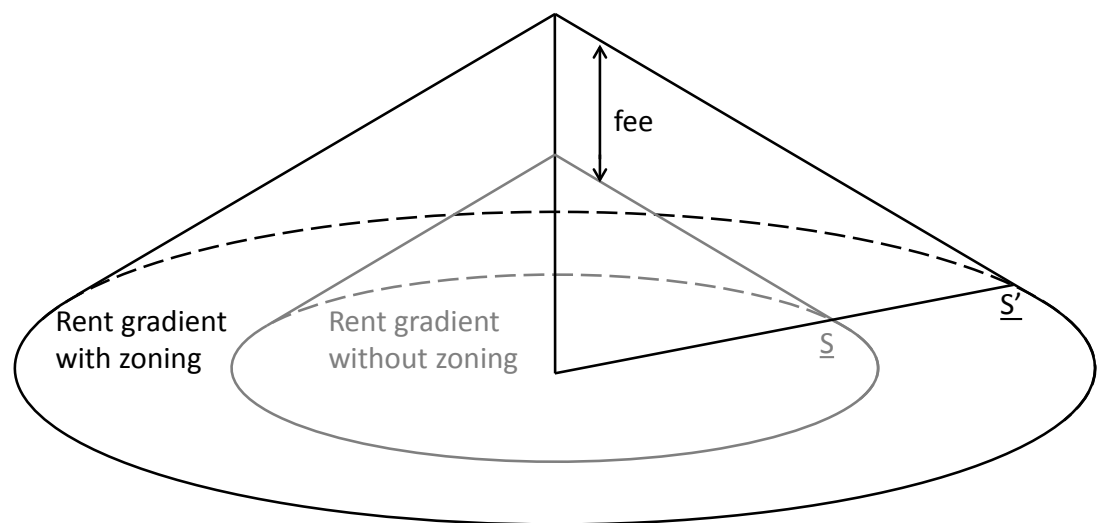

\footnotetext{
${ }^{11}$ The benefit individuals receive living in city $j$ is given by $U\left(x, h ; Q_{j}\right)=x+y+Q_{j}=w_{j}+I+1-p_{j}-$ $w_{j} \tilde{c}_{j} N_{j}^{1 / 3}+Q_{j}$. To write the utility in terms of only population, replace $w_{j}=A_{x, j} N_{j}^{\alpha}$.
} 


\subsection{Barriers to Migration}

This section introduces the four policies (or lack of) that create different barriers to migration in the first stage. These policies affect the mobility of individuals in the second stage. The following cases introduce the objective function of the city creator that has the policy decision to make in the first stage and the mobility condition that characterizes the equilibrium in the second stage.

\section{Case 1: Planner with City-Specific Taxes}

The planner's objective is to maximize the total benefit created in the system of cities. In the first stage, the planner establishes cities and sets a city-specific $\operatorname{tax} \tau_{j}$, which is paid by all individuals residing in the city. ${ }^{12}$ The population, $\mathcal{N}_{j}(\tau)$, in city $j$ is a function of the vector of city specific taxes, $\tau=\left(\tau_{1}, \tau_{2}, \ldots, \tau_{J}\right)$, characterized by the mobility condition

$$
b_{i}\left(\mathcal{N}_{i}(\tau)\right)-\tau_{i}=b_{j}\left(\mathcal{N}_{j}(\tau)\right)-\tau_{j} \quad \forall i, j \in \mathcal{K}
$$

This condition ensures the payoff individuals receive, the average benefit net taxes, is the same across all inhabited cities $\mathcal{K}$. The planner establishes the set of cities $\mathcal{K}$ and sets the city-specific taxes $\tau$ to maximize,

$$
\sum_{j \in \mathcal{K}} \mathcal{N}_{j}(\tau) b_{j}\left(\mathcal{N}_{j}(\tau)\right)
$$

\section{Case 2: Individuals with with Exclusionary Power (Local Governments)}

In this case, an individual that establishes a city in the first stage acts as the local government with the ability to set a population limit for that city. The objective of the local government is to maximize the average benefit produced in the city. Therefore, in stage 2 the population of city $j$ is characterized by,

$$
\frac{\partial b_{j}\left(N_{j}\right)}{\partial N_{j}}=0 \quad \forall j \in \mathcal{K},
$$

replacing the mobility condition in this case. As will become apparent, all cities in this case will be at their population limit and some individuals will inhabit the hinterland.

\footnotetext{
${ }^{12}$ The tax revenue is redistributed evenly as a lump-sum to all individuals in the system of cities. The tax rate can therefore be thought of as $\tau_{i}=\hat{\tau}_{i}-\bar{\tau}$, where $\hat{\tau}$ represents the city specific tax and $\bar{\tau}$ represents the population weighted average tax rate.
} 
Case 3: Individuals without Policy (Free Mobility)

In this case, an individual that establishes a city in the first stage is unable to impose any barriers to migration. In the second stage individuals decide which city to move to, unimpeded by taxes, fees, or population limits. The mobility condition states the benefit individuals receive, in equilibrium, is equal across all established cities,

$$
b_{i}\left(N_{i}\right)=b_{j}\left(N_{j}\right) \equiv \bar{b} \quad \forall i, j \in \mathcal{K},
$$

where $\bar{b}$ is the endogenous level of benefit all individuals in the system of cities receive. ${ }^{13}$

Case 4: Individuals with a fee (Zoning)

In this case, an individual that establishes a city in the first stage is allowed to set a fee that is paid by all individuals that move into the city. The population, $\mathcal{N}_{j}(f)$, in city $j$ is a function of the vector of fees, $f=\left(f_{1}, f_{2}, \ldots, f_{J}\right)$, set by decentralized individuals that create cities. Population in city $j$ is characterized by the mobility condition that ensures the payoff individuals receive, the average benefit net fees, is the same across all inhabited cities,

$$
b_{i}\left(\mathcal{N}_{i}(f)\right)-f_{i}=b_{j}\left(\mathcal{N}_{j}(f)\right)-f_{j} \quad \forall i, j \in \mathcal{K}
$$

The individual that creates city $j$ lives in city $j$ and receives the average benefit net of fees, that is common across all cities. Therefore the objective of the individual that sets the fee is to maximize revenues from free,

$$
\max _{f_{j}} \quad f_{j} \mathcal{N}_{j}(f),
$$

understanding population in the city depends on the fee. ${ }^{14}$

\footnotetext{
${ }^{13}$ The average benefit individuals receive in a system of free mobility $\bar{b}$ equals the average benefit in the hinterland if the hinterland is inhabited, otherwise $\bar{b} \geq \bar{y}$.

${ }^{14}$ Maximizing the profit from fees is the correct objective function for the city creator because population is assumed to be a real number. To understand this intuition, consider the more general objective function $\Omega(\omega) b_{j}\left(N_{j}(f)\right)+f\left[N_{j}(f)-\Omega(\omega)\right]$ where $\Omega$ is the density function of population and $\Omega(\omega)$ represents the density at point $\omega$ which represents the city creator. In the case where population is an integer $\Omega(\omega)=1$, representing a unit mass for each individual. However, in the case where population is a real number $\Omega(\omega)=0$. Substituting $\Omega(\omega)=0$ into the more general objective function we note that it reduces to maximizing the revenue from the fees.
} 


\section{Results}

This section derives a general solution that fully characterizes (i) the global optimum implemented by the planner, (ii) the outcome produced under local governments with exclusionary power that set population limits to produce local optimums, (iii) the market outcome with free mobility, and (iv) the market outcome with a price mechanism where individuals that create cities are allowed to charge future entrants a fee. Throughout the analysis I maintain the assumption that there is sufficient population such that the hinterland is always inhabited in equilibrium. This assumption simplifies the exposition without much loss in generality.

Section 4.1 defines the equilibrium and general set of assumptions. Section 4.2 derives the solution for each set of barriers to migration. This solution is used to prove propositions 1-3. A brief discussion follows in section 4.3 .

\subsection{Preliminaries}

The model defines a game with homogeneous players with a set of strategies $n_{1} \in \mathcal{J}$, and $n_{2} \in \mathcal{K}$ which define the city $n_{1}$, which the player establishes in the first stage, which may be zero, and the city $n_{2}$, which the player moves to in the second stage. Each player receives the average benefit of the city she lives in, plus the fee revenue if she establishes a city and is allowed to charge a fee.

ASSUMPTION The average benefit functions $b_{j}\left(N_{j}\right)$ are continuously differentiable, concave, strictly increasing and then strictly decreasing, but at a slower rate, in population $N_{j}$.

Assumption A provides the smoothness of the benefit function that ensures the existence of an equilibrium and the marginal benefit $m b_{j}\left(N_{j}\right)=N_{j} b_{j}^{\prime}\left(N_{j}\right)+b_{j}\left(N_{j}\right)$.

DEFINITION Stable Population. A population is stable if it is greater than or equal to the population that maximizes the average benefit in a city.

Throughout the analysis, attention is restricted to trembling-hand perfect Nash equilibria (Selten, 1975). ${ }^{15}$ An equilibrium is characterized by the set of cities established $\mathcal{K} \subseteq \mathcal{J}$ and the population distribution $D(\mathcal{K})=\left\{N_{0}, N_{1}, N_{2}, \ldots, N_{K}\right\}$ across established cities and the

\footnotetext{
${ }^{15}$ For every finite extensive-form game with perfect information there exists at least one trembling hand perfect Nash equilibrium. This restriction rules out unstable equilibria that in the literature are typically restricted through the use of a stability condition. For example, $b_{j}^{\prime}\left(N_{j}\right) \leq 0$ for inhabited cities, which states that the slope of the average benefit function is negative for all cities.
} 
hinterland.

The trembling hand perfect Nash equilibria restricts population in each inhabited city $j$ to be a stable population. Consider cities 1 and 2 that both provide the same payoff (the average benefit in the city net any taxes or fees) but city 1 has a stable population and city 2 does not. Consider a slight perturbation in which an individual from city 1 is moved to city 2 . In this case the average benefit increases faster in city 2 , by assumption, and there is an incentive for more individuals to move from city 1 to city 2 . Therefore, there cannot be a trembling hand perfect Nash equilibria where one city does not have a stable population.

The equilibrium of the subgame in the second stage is characterized by the population distribution $D(\mathcal{K})=\left\{N_{0}, N_{1}, N_{2}, \ldots, N_{K}\right\}$, where $N_{0}$ denotes the population in the hinterland. The population distribution is an equilibrium of the subgame if and only if the mobility constraint is met. By construction, if the mobility constraint is met there is no profitable deviation for an individual to move to a different city in the second stage. Further, suppose toward contradiction that an equilibrium exists such that the mobility constraint is not met. In this case the average benefit, net any taxes or fees, must be greater in some city $i$, than in another city $j$. If the average benefit, net any taxes or fees, is greater in a given city $i$ than in city $j$ then an individual that decided to move to city $j$ in the second stage could deviate and move to city $i$ instead and receive a higher payoff, contradicting this as an equilibrium.

\subsection{Solution}

This section solves the equilibrium set of inhabited cities $\mathcal{K}$ and population distribution $D(\mathcal{K})$, for each of the four cases. First, the social optimum is found as the solution to the planner's problem. The distortions that exist in the other three cases are determined by comparing the equilibria in those cases with the planner's solution. These comparisons lead to propositions $1-3$.

\subsubsection{Planner with Taxes (Social Optimum)}

The planner maximizes the objective in equation (5) subject to the mobility condition given in equation (4) by creating the set of cities $\mathcal{K}$ and by setting the city-specific taxes $\tau$ that act as barriers to migration.

\section{i) Population Distribution}

The equilibrium taxes are found by taking the first order condition of the objective 
function with respect to $\tau$ subject to the constraint that the sum of populations across established cities and the hinterland is equal to the total population, $\sum_{j=0}^{J} x_{j} N_{j}=N$. The first-order condition states that the maximum benefit is produced when the marginal benefits across all established cities and the hinterland are equal, $b_{j}\left(N_{j}\right)+b_{j}^{\prime}\left(N_{j}\right) N_{j}=\lambda$ where $\lambda$ is the lagrangian multiplier.

The optimal tax rates are found by combining the first order condition with the mobility condition, $\tau_{j}=b_{j}^{\prime}\left(N_{j}^{*}\right) N_{j}^{*}$, where $N_{j}^{*}$ is the equilibrium level of population in city $j$ in this case. The equilibrium of the subgame in the second stage for the planner is characterized by the updated mobility condition,

$$
b_{j}\left(N_{j}^{*}\right)+b_{j}^{\prime}\left(N_{j}^{*}\right) N_{j}^{*}=b_{i}\left(N_{i}^{*}\right)+b_{i}^{\prime}\left(N_{i}^{*}\right) N_{i}^{*} \quad \forall j, i \in \mathcal{K}
$$

The equilibrium mobility condition given in equation (10) defines the socially efficient population distribution $D(\mathcal{K})$ as a function of the set of cities $\mathcal{K}$ that are established.

\section{ii) Set of Cities}

The planner establishes the cities that will maximize total benefit taking into account the heterogeneity across cities in production amenities $A_{j}$ and quality of life amenities $Q_{j}$, according to equation (1). To order cities that are heterogenous in two-dimensions this section develops two projections that map $A x Q$ space to $\tilde{A}$ space. These projections are similar to the equivalent and compensating variation introduced by John Hicks in 1939, which project price-wealth space onto a fixed price line.

The first mapping projects production and quality of life amenities onto a fixed amenities line, holding population fixed. This mapping gives the amount of change in quality of life amenities needed to offset a change in production amenities in a city such that the residents of the city receive the same benefit with the same level of population, similar to the equivalent variation. This projection is the indifference curve between production and quality of life amenities given by,

$$
Q_{j}=\bar{C} N_{j}^{\gamma}-A_{j} N_{j}^{\alpha+\gamma}+B N_{j}^{\beta+\gamma}
$$

The slope of the indifference curve is given by $N_{j}^{\alpha+\gamma}$.

The second mapping compares the equilibrium level of benefit for two different production amenity levels allowing equilibrium populations to differ. This mapping is similar to the compensating variation that compares utility levels, allowing individuals to choose different 
bundles for different relative prices.

Panel A of Figure 4 depicts a city before and after a positive productivity shock. The equivalent and compensating variation benefit determines the difference in utilities before and after the productivity shock, denoted by $\psi$. In exchange for this productivity shock individuals would be willing to forgo quality of life amenities, $Q=\psi N^{\gamma}$.

In Panel A, the population allocated by the planner is given by the point where the marginal benefit curve intersects the marginal benefit in all other cities, denoted by the outside option and depicted as the dashed horizontal line. The equivalent variation benefit is given by the difference in the average benefit curves at the old population level. The compensating variation benefit is given by the difference in the average benefit at the old population level and the average benefit at the new population level. In this case, the compensating variation benefit is smaller than the equivalent variation because as a result of the positive productivity shock the efficient population in the city increases and the increase in population erodes some of the benefits from the positive productivity shock for the initial residents of the city.

Panel B of Figure 4 depicts the compensating variation benefit for the planner in terms of the whole city. Intuitively, this combines the benefits for the people initially living in the city with the benefits of people moving from the hinterland to the city. The benefit for the people initially in the city is given by compensating variation benefit for a single person, from Panel A, multiplied by the number of people living in the city before the productivity shock (depicted as the long narrow horizontal gray rectangle). The benefit for the people moving from the hinterland to the city after the productivity shock is given by the difference in the average benefit in the hinterland, the horizontal dashed line, and the average benefit in the city after the productivity shock multiplied by the number of people that move into the city (depicted as the vertical gray rectangle). Together these benefits give the compensating variation benefit for the whole city. 
Figure 4: Planner (Efficient) and Zoning: Equivalent and Compensating Variation

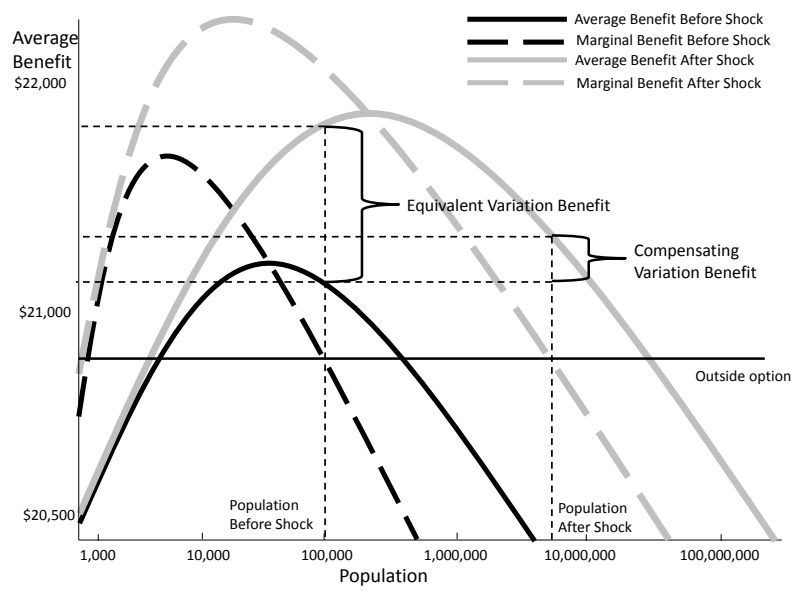

A) One Person Comparison

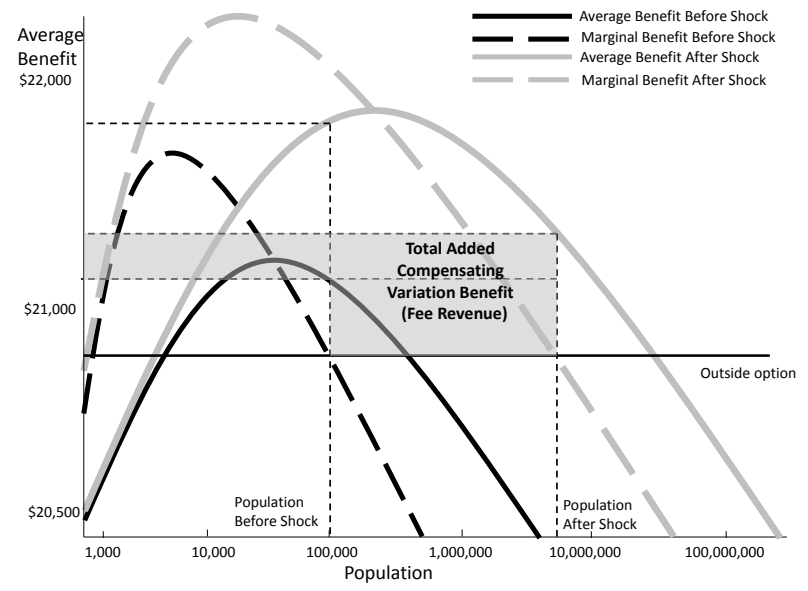

B) Whole City Comparison

The two projections allow the planner to create the efficient order cities should be created given different total population levels. The planner has an incentive to continue to create cities to increase total benefit. Therefore, the planer creates cities until the next established city would be unstable.

The set of cities, $\mathcal{K}$, created by the planner is characterized by the projection given in equation (11) and the condition that the planner continues to create cities until the next city would not have a stable population.

\subsubsection{Systems of Cities With Local Governments and Free Mobility}

PROPOSITION 1 A system of cities with individuals with exclusionary power produces weakly too many underpopulated cities that are biased toward cities with high levels of quality of life amenities.

PROPOSITION 2 A system of cities with free mobility produces weakly too few overpopulated cities that are biased toward cities with high levels of production amenities.

Figure 1 depicts the population distributions with local governments and free mobility, points $\mathrm{B}$ and $\mathrm{C}$ respectively, that are characterized by the mobility conditions in equations (7) and (6). Point A in Figure 1 depicts the efficient population for the city characterized by the point at which the marginal benefit in the city is equal to the hinterland marginal benefit. In contrast, local governments do not allocate enough population, point $\mathrm{B}$, as they maximize 
the average benefit within city $j$ but not across all cities. ${ }^{16}$ In contrast, free mobility allocates too much population to city $j$ because individuals move between the city and the hinterland setting the average, instead of the marginal, benefits equal; the neoclassical distortion.

The tradeoff between production and quality of life amenities depends on the equilibrium level of population because the slope of the mapping in equation (11) depends on population. Because systems of cities with free mobility weakly overpopulate cities these systems overvalue production amenities relative to the planner. Similarly, systems of cities with local governments overvalue quality of life amenities because they weakly underpopulate cities. ${ }^{17}$

The intuition follows from the mechanisms by which production and quality of life amenities affect cities. Production amenities increase the efficiency of all individuals which has positive spillover effects. In contrast, population has a weakly negative spillover on quality of life amenities. Therefore, production amenities are valued more by systems of cities with larger city populations because the spillover effects are larger.

Figure 5 depicts the equivalent and compensating variation benefits for local governments and free mobility. For local governments the compensating is greater than the equivalent variation benefit because the exclusionary power allows the local governments to capture the full benefit of the production amenity increase. In contrast, the compensating variation benefit for individuals in a city with free mobility is zero because individuals from the hinterland move into the city until the average benefits are again equal.

\footnotetext{
${ }^{16}$ The population that maximizes the average benefit in a given city is the minimum stable population and therefore the local government population is weakly smaller than the efficient population for the city. When cities are homogenous maximizing the average benefit in every city is the same as maximizing the total benefit across all cities. However, when cities are heterogeneous it becomes efficient to allocate more population to cities with higher amenity levels.

${ }^{17}$ Similarly, systems of cities with free mobility and local governments have incentives to create socially inefficient number of cities. For a further discussion see Appendix A:.
} 
Figure 5: Local Government and Free Mobility Equivalent and Compensating Variation

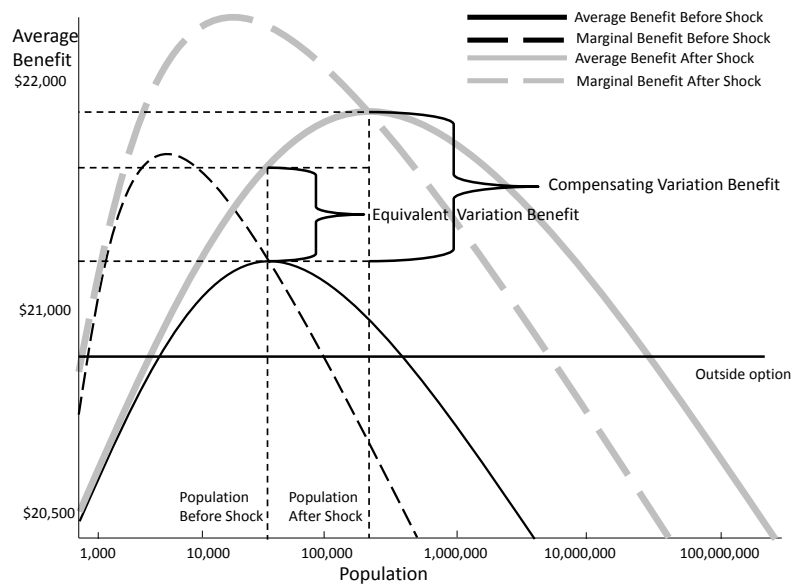

A) Local Governments

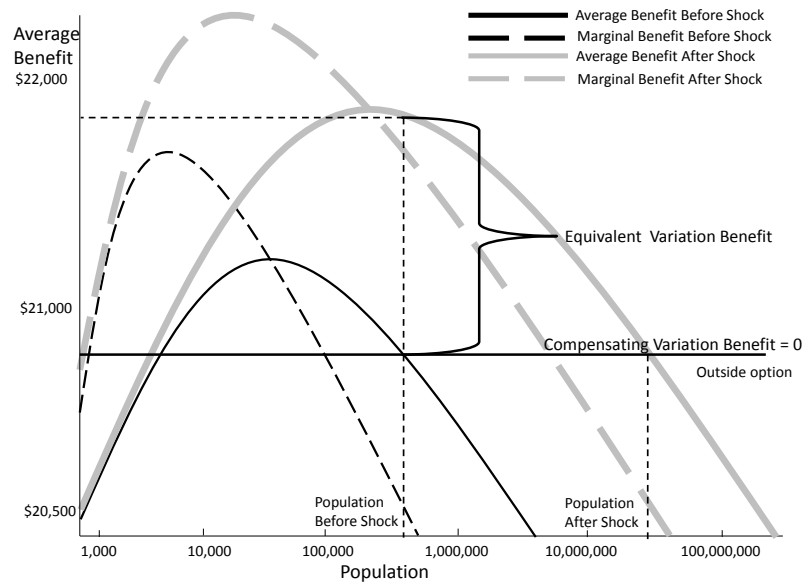

B) Free Mobility

\subsubsection{Zoning: Individuals With a Price Mechanism}

PROPOSITION 3 A system of cities with individuals with a price mechanism produce the efficient distribution of population across the efficient set of cities.

Proposition 3 follows from comparing the planner equilibrium with the equilibrium with individuals with a price mechanism that is characterized below.

\section{i) Population Distribution}

Each city is created by an individual that is allowed to set a fee that individuals that live in the city must pay. City creators do not care about maximizing benefit either within or across cities. The objective of each individual is to maximize revenue from the fees they charge, given in equation (9). The equilibrium fees are found by taking the first order condition of the objective function for each city creator substituting the mobility condition given in equation (8) into the objective function. The first order condition, rearranged, gives, ${ }^{18}$

$$
f_{j}=-N_{j} b_{j}^{\prime}\left(N_{j}\right) .
$$

\footnotetext{
${ }^{18}$ The objective function substituting in the mobility condition is given by $f_{j} b_{j}^{-1}\left(b_{i}\left(N_{i}\right)-f_{i}+f_{j}\right)$. The firstorder condition is given by $f_{j} b_{j}^{-1^{\prime}}+b_{j}^{-1}=0$, assuming the number of cities is large such that $\partial N_{i} / \partial f_{j}=0$. For a detailed discussion of when this condition is likely to hold, see Salant and Seegert (2014). The condition automatically holds if there is positive population living in the hinterland $N_{0}>0$. Substituting in the relationship that $b_{j}^{-1}=N_{j}$ and $b_{j}^{-1^{\prime}}=1 / b_{j}^{\prime}$ gives the relationship $f_{j}=-N_{j} b_{j}^{\prime}\left(N_{j}\right)$, given in the text.
} 
The equilibrium of the subgame in the second stage for the price mechanism is characterized by the updated mobility condition,

$$
b_{j}\left(N_{j}\right)+b_{j}^{\prime}\left(N_{j}\right) N_{j}=b_{i}\left(N_{i}\right)+b_{i}^{\prime}\left(N_{i}\right) N_{i} \quad \forall j, i \in K
$$

The equilibrium condition in the second stage for the price mechanism is the same as the second stage equilibrium condition for the planner. Therefore given a set of cities the price mechanism produces the efficient allocation of population.

\section{ii) Set of Cities}

In the first stage each individual decides whether to create a city or wait until the second stage and move to one of the cities created by others in the first stage. An individual that moves to an existing city receives the average benefit in the city net of the fee to live in the city, $b_{j}\left(N_{j}\right)-f_{j}$. An individual that creates a city in the first stage receives the average benefit in the city net of the fee plus all of the fee revenue, $b_{j}\left(N_{j}\right)-f_{j}+f_{j} N_{j}$. In the second stage individual optimization ensures the the average benefit net of the fee offered in all cities is the same. Therefore an individual in the first stage will create a city if the equilibrium fee is positive.

The equilibrium fee is given by the difference between the average and marginal benefit produced in a given city, given in equation (12). The difference between the average and marginal benefit is positive for all stable populations. For a given order of cities, individuals

will create as many cities as can be created such that all cities have stable populations, the same condition as the planner.

Figure 4 panel B depicts the added fees after the productivity shock, the compensating variation in this case. The total fee collected is given by the fee, given by the difference between the benefit provided in the hinterland and the average benefit in the city, multiplied by the number of people in the city that pay the fee. Panel B of Figure 4 shows the increase in fee revenue the city creator collects after a positive productivity shock. The fee collection increases because the equilibrium fee increases and more people live in the city and thus pay the fee. This demonstrates graphically the surprising result that the city creator allowed to charge a fee and the planner value amenities in the same way. 


\subsection{Discussion}

i) Discussion of the generality of proposition 3

The equilibrium fee a city creator is able to charge is weakly decreasing in the number of cities created. However, when an individual decides to create a city in the first stage they do not consider the negative impact they have on other individuals that created cities. However, if individuals were able to establish multiple cities and charge a fee, they would be forced to account for decreased equilibrium fees and proposition 3 would not hold. Interestingly, if one individual were able to establish all cities and charge a fee proposition 3 would again hold, though the equilibrium fee in each city would be higher. These results extend the intuition from Knight (1924)'s observation that revenue-maximizing toll setters produce the efficient distribution of cars across two roads to the extensive margin where the number of cities is endogenous. ${ }^{19}$

\section{i) Discussion Set of Cities}

Figure 6 plots a subset of cities, their amenity levels (estimated in the following section), and possible indifference curves for systems of cities determined by the planner, local governments, and free mobility. In this example, all of the indifference curves intersect New Orleans, LA, which has an intermediate level of quality of life and production amenities from which to compare with other cities. For example, in comparison to St. Louis, MO, New Orleans, LA has more production and quality of life amenities resulting in New Orleans, LA being ranked higher than St. Louis in all three cases. In contrast, in all three cases Los Angeles, CA and San Francisco, CA are preferred over New Orleans, LA.

The more interesting comparisons are with Portland, OR and Houston, TX because these cities are preferred to New Orleans, LA in some cases but not others. Portland, OR has more quality of life amenities than New Orleans, LA but less production amenities. The planner and systems of cities with free mobility prefer New Orleans, LA over Portland, OR but systems of cities with local governments prefer Portland, OR. Similarly, Houston, TX is preferred over New Orleans, LA by systems of cities with free mobility but not by the planner or systems of cities with local governments because Houston, TX has relatively higher levels of production amenities than quality of life amenities. Interestingly, Portland, OR is known for their land use laws while Houston, TX is known for having no zoning laws-consistent

\footnotetext{
${ }^{19}$ For a detailed discussion of Knight (1924)'s extensions and limitations to markets with congestion see Salant and Seegert (2014).
} 
with the model where quality of life amenities are overvalued by systems of cities with more exclusionary power.

Figure 6: Equivalent Variation Indifference Curves

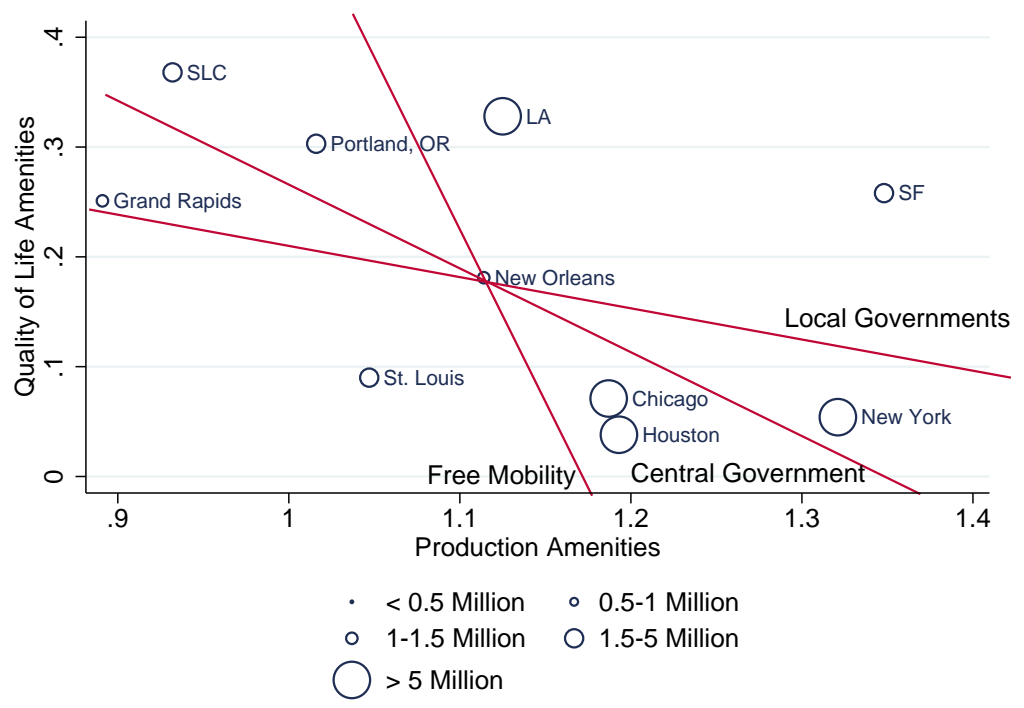

\section{Amenity Level Estimation}

This section derives a series of moment conditions that link the micro-founded model with data on wages, rents, commute times, population, and density. These moment conditions provide three important extensions to previous estimation strategies. First, the model explicitly accounts for agglomeration effects, which are fundamental to cities. Urban economists have long modeled and estimated the benefits of concentrating people and production (Alonso, 1964; Mills, 1967; Muth, 1969). ${ }^{20}$ Modeling agglomeration explicitly is necessary to separate the agglomeration benefits and amenity levels, which are linked through population growth. Cities with more amenities attract more people, through higher wages or higher quality of life, which creates larger agglomeration effects that increase wages and attract more people. Incorrectly, assuming higher wages are entirely due to production amenities will bias

\footnotetext{
${ }^{20}$ The benefits from concentrating people and production may be due to sharing intermediary goods and specialized labor, better matching of skills to firms, or other spillover effects discussed in detail in Duranton and Puga (2004). In addition these benefits may be industry specific or general to population and specifically its density Murphy (2013).
} 
amenity estimates toward cities that have large populations, and thus agglomeration benefits, for historical reasons. Separating these effects is important to ensuring policies are encouraging concentration of people and production in the most advantageous locations for the 21 st, rather than 17 th, century.

Second, accounting for density is important because it affects the tradeoff between agglomeration and urban costs. Denser cities are able to benefit from larger agglomeration effects while dampening some urban costs. ${ }^{21}$ The density of cities is partly an endogenous decision on the part of cities that are able to set zoning laws, provide mass transportation, and provide investment incentives. All of these factors effect the mobility of individuals into a city. For example, strict zoning laws artificially decrease housing supply and increase rents, which if ignored would be attributed to higher quality of life amenities. Therefore, allowing densities to differ across cities is important in separating the effects of agglomeration and amenity levels on wages and rents.

Third, the diagonally weighted minimum distance estimation allows for nonlinear effects that exist within cities. For example, rents within a city do not linearly increase with production amenities. Loosening the linearity assumption also eliminates the need for the assumption that all cities are a small deviation from the average city. In some contexts the small deviation assumption may be unimportant if the data lack extreme outliers or the estimates for these outliers is unimportant. In contrast, the distribution of cities has large outliers and the estimates for these outliers are of extreme importance for efficiency.

\subsection{Moment Conditions}

Four sets of moment conditions are derived from the micro-founded example in section 3.2. These moment conditions are used to estimate two common variables, agglomeration and commuting costs, and three city-specific variables, amenity levels in tradeable production, housing production, and quality of life.

The first set of moment condition relates the city-specific wage with the population, agglomeration, and city-specific production amenities that exist,

$$
w_{j}=A_{x, j} N_{j}^{\alpha}
$$

\footnotetext{
${ }^{21}$ Certainly, there are costs due to density including the concentration of pollution, traffic, and disease transmission. However, the concentration of business in New York City may not be possible if the city's density was that of an average average suburban community, the commute for the furthest resident could be longer than the hours they would be able to work.
} 
Wages are higher in cities with more production amenities, $A_{x, j}$, and more population, $N_{j}$, because of the benefits of agglomeration. This condition explicitly takes into account that cities may offer higher wages because they have larger population, perhaps for historical reasons, or because they have more production amenities, such as ports.

The second set of moment conditions uses the equilibrium mobility condition, that utility across cities, conditional on the barriers to migration captured by $A_{h, j}$, must be equal. The common benefit each city provides is derived as, $b_{j}\left(N_{j}\right)=w_{j}\left(1-\tilde{c}_{j} N_{j}^{1 / 3}\right)-r_{T, j}+Q_{j}+I+1$, where $r_{T, j}$ is the average rent inclusive of housing and land. Rearranging the mobility condition demonstrates that the average rent in city $j$ increases with quaility of life amenities and the city-specific wage, net of taxes and commuting costs,

$$
r_{T, j}=w_{j}(1-\tau)\left(1-\tilde{c}_{j} N_{j}^{1 / 3}\right)-\bar{C}+Q_{j}
$$

All benefits common across cities are captured in the term $\bar{C}$.

The third set of moment conditions derives the density of the city,

$$
\delta_{j}=\left(\frac{2}{3}\right)^{2 / 3} A_{h, j}^{2 / 3}\left(\frac{N_{j}}{\pi}\right)^{1 / 3}
$$

which depends on the population of the city and the housing production amenities of the city. The model captures the empirically observed dynamic that cities with higher populations are more dense. In addition, this condition allows for differences in housing productivity, including endogenous zoning laws, to affect the density of a city.

The fourth set of moment conditions uses the average commute time in city $j, \bar{C}_{j}$, to estimate the common congestion parameter $c$,

$$
\bar{C}_{j}=(3 / 4)\left(3 /\left(2 \pi A_{y, j}\right)\right)^{1 / 3} c N_{j}^{1 / 3}
$$

These four sets of moment conditions are used to estimate the two common parameters $c$ and $\alpha$, which capture the congestion and agglomeration that occurs in cities, and the three city-specific amenity levels $Q_{j}, A_{x, j}$, and $A_{h, j}$, which capture quality of life amenities and production amenities in the tradeable and housing sectors. In total there are 1128 moments to estimate the 848 variables of the model. The diagonally weighted minimum distance estimation uses the series of moment conditions weighted by the diagonal of the variance-covariance matrix of the moment conditions. The variance-covariance matrix is 
calculated using the data on wages, rents, density, and commute times described in the following subsection.

\section{$5.2 \quad$ Data}

The American Community Survey is used to provide detailed information on wages, rents, commute times, population, and density of cities. The one percent sample includes roughly three million individual observations in 2009 and these individuals are identified at the PUMA level. PUMAs are geographical regions that do not correspond to counties but in most cases can be aggregated up into counties; for instance dense counties will encompass numerous PUMAs. ${ }^{22}$ Cities are defined as metropolitan statistical areas (MSAs) where Consolidated MSAs are considered a single city (e.g. New York includes Long Island and northern New Jersey). This definition creates 282 cities.

Cities in this study are defined as a consolidated group of counties. However, in practice, the urban area of a city is sometimes smaller than the land area of the consolidated group of counties. To correct for this measurement of cities the density of a city is calculated as the weighted mean of the county densities, where a county's weight is given by the percentage of the city population living in the county. This density measurement is a better approximation of the average effective density within the city and is similar to the density measures used by Glaeser and Kahn (2004) and Rappaport (2008).

Individuals with different skill levels may choose to live in different cities, causing wages to differ across cities for reasons other than differences in amenity levels. To control for these skill differences this study focuses on the unexplained component of wages $w_{i}=\log \left(W_{i}\right)-Z_{i}^{\prime} \Gamma$ where $Z$ is a vector of worker characteristics and $\Gamma$ is the vector of coefficients from a regression of the logarithm of wages on the worker characteristics. For scaling purposes in the diagonally weighted minimum distance estimation the unexplained component is combined with the average wage across all cities. This method for calculating the unexplained component of wages is similar to studies using wage and price differentials to look at differences in amenity levels (Gabriel and Rosenthal, 2004) and provides similar estimates.

Figure 7 graphs the relationship between average rent and average unexplained wages across cities, where population is denoted by the size of the marker. Figure 8 graphs the relationship between average commute times and city density. The left panel, in both figures,

\footnotetext{
${ }^{22}$ Some PUMAs encompasses regions in multiple counties in which cases observations are weighted to aggregated to the county level; this occurs mostly in rural areas which are not used in the estimation.
} 
depicts all cities and the right panel depicts a subset with labels. These figures demonstrate the positive correlation between wages and rents and between commute times and densities. These figures also demonstrate the deviations from these trends, which intuitively provide the variation to identify the city-specific amenity levels. For example, cities with relatively higher rents than wages (such as Honolulu, San Francisco, and Salt Lake City) must be compensated with higher levels of quality of life amenities.

Figure 7: Average Rent and Wage
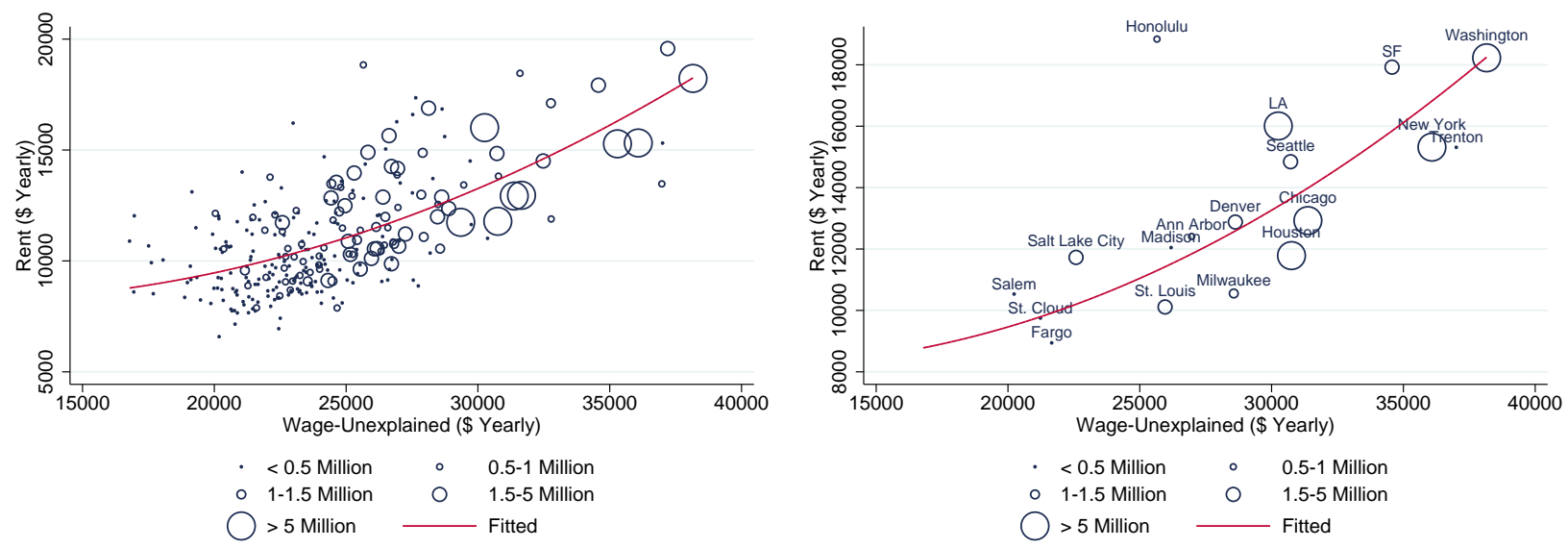

Figure 8: Average Time Commuting and Density
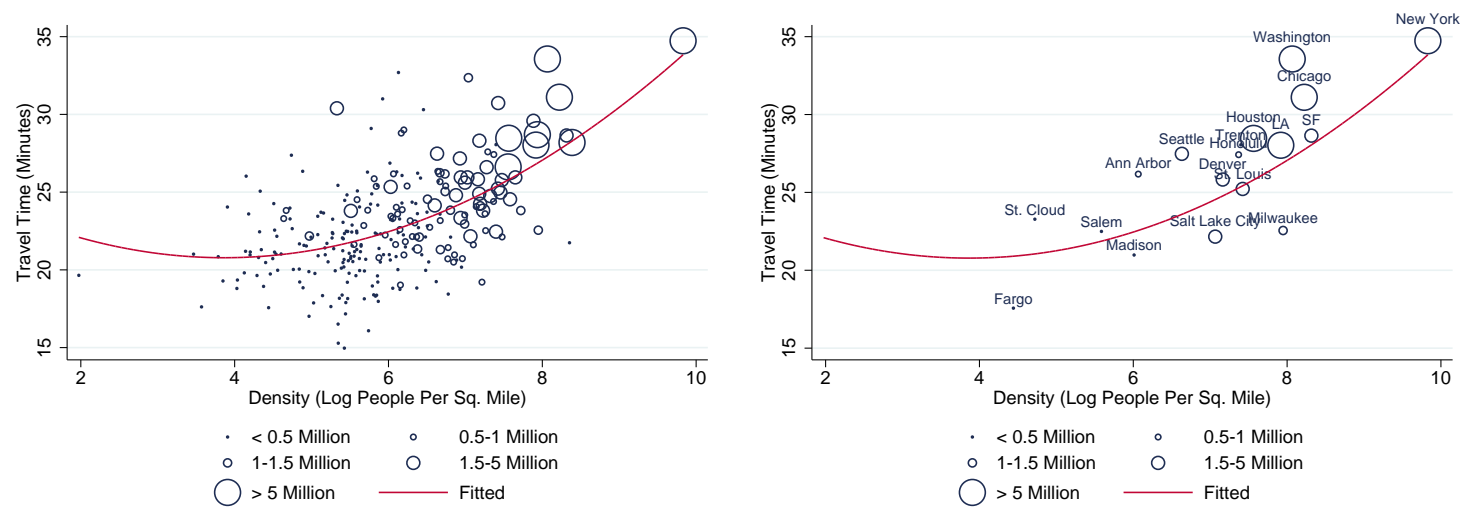

\subsection{Amenity Level Estimates}

The diagonally weighted minimum distance estimation uses the 1128 moments to estimate the 848 variables of the model. Table 1 reports the top twenty cities in each of the three amenity levels. The estimates for all cities are reported in the appendix in Tables A.1-A.5. 
The goal is to estimate the location specific amenities that can not be recreated, for example New York City's port or the weather of Honolulu that would be impossible to recreate in Omaha, Nebraska. Theoretically, if the population of New York City was moved to Omaha, Nebraska then the amenities endogenous to population, such as a world class opera company, would exist in Omaha. The location specific amenities are important for determining which cities are under and over populated, perhaps for path dependent reasons, relative to the amenities they provide.

The value of different quality of life and production amenities may have changed through time. For example, the productivity amenity of access to navigable water may have been more important in the 18th and 19th centuries than now in the 21st century. Cities that initially thrived because of these production amenities may still be growing due to agglomeration benefits and path dependence. However, to the extent possible, policies should be implemented to encourage growth in cities with high amenities for the economy today. For example, many cities in the southern United States are now more productive with the widespread adoption of air conditioning, however population may be slow to adjust to these cities with better amenities. This may become more important as global climate change affects both the productive and quality of life amenities of cities.

The most productive cities, reported in Table 1, are a combination of cities that have attracted financial companies (e.g. Stamford and Hartford, CT), technology companies (e.g. San Jose and San Francisco, CA), and traditional harbor cities (e.g. Galveston, TX and Anchorage, AK). Many of the most productive cities are in close proximity to each other suggesting that there may be a benefit of being close to another productive city. For example, eight of the top twenty most productive cities are within 120 miles of New York City. The cities with the most housing production seem to be a combination of cities with high densities (e.g. New York, NY and Charlottesville, VA) and cities that may be cheaper to build in because of the cost of land (e.g. Cleveland, OH and Athens, GA).

The cities with the highest quality of life include some traditional vacation locations, for example, Honolulu, HI which tops the list. Many of the cities in the top twenty quality of life amenity cities have very low housing amenities. In the full sample there is a negative correlation between housing production amenities and quality of life amenities. This is consistent with cities with high quality of life amenities attempting to pass zoning laws to monopolize these amenities or that areas that have the ability to pass strong zoning laws over value quality of life amenities. 
Figure 9 graphs the production and quality of life amenities for all cities (left panel) and a subset of cities (right panel). There is a negative correlation between production and quality of life amenity cities. Larger circles on the graph denote cities with larger populations. Cities with high levels of production amenities tend to have more population while cities with high levels of quality of life amenities tend to have less population. This is consistent with the model, where cities with free mobility become larger and tend toward cities with high production amenities and cities with exclusionary power remain smaller and over value high quality of life amenities.

The agglomeration and urban cost parameters common across all cities are reported in Panel D of Table 1. Accounting for the tradeoff between agglomeration and congestion is important to provide consistent estimates of the amenity levels. In addition, these estimates provide some external validity to the diagonally weighted minimum distance estimation. For example, the 0.049 agglomeration parameter estimate is consistent with Behrens et al. (2010) estimate of 0.051 and the meta-analysis by Rosenthal and Strange (2004).

Figure 9: Amenity Levels
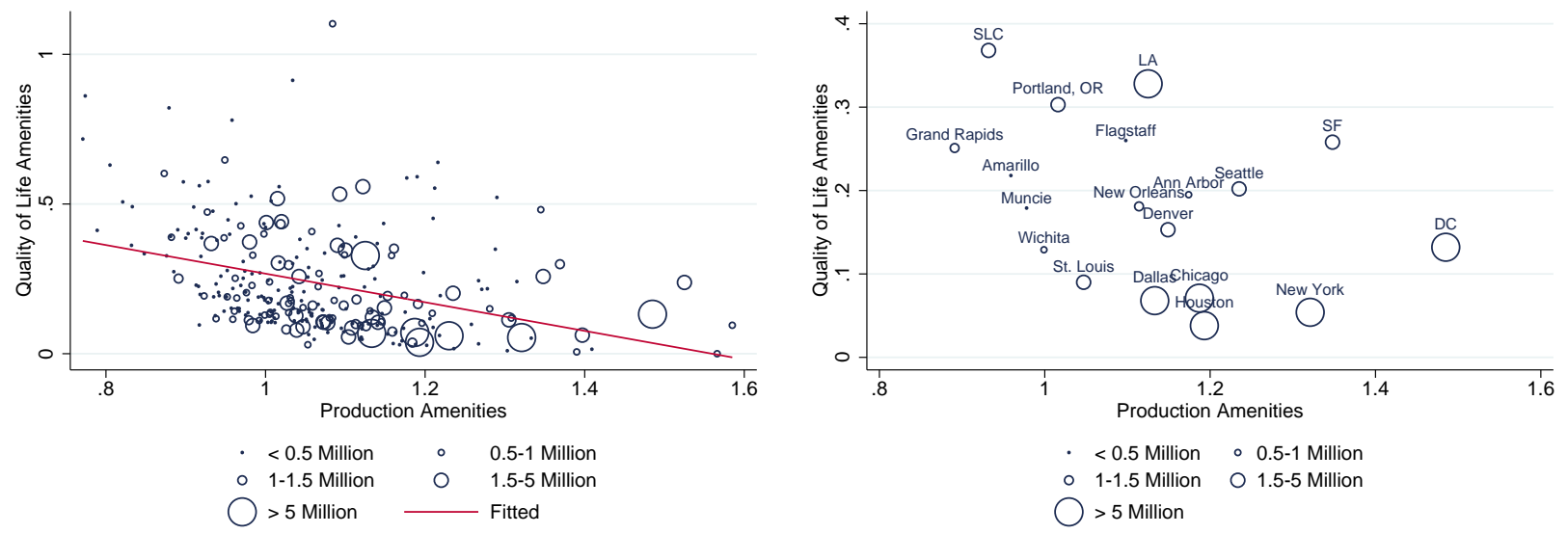
Table 1: Amenity Level, Agglomeration, and Urban Cost DWMD Estimates

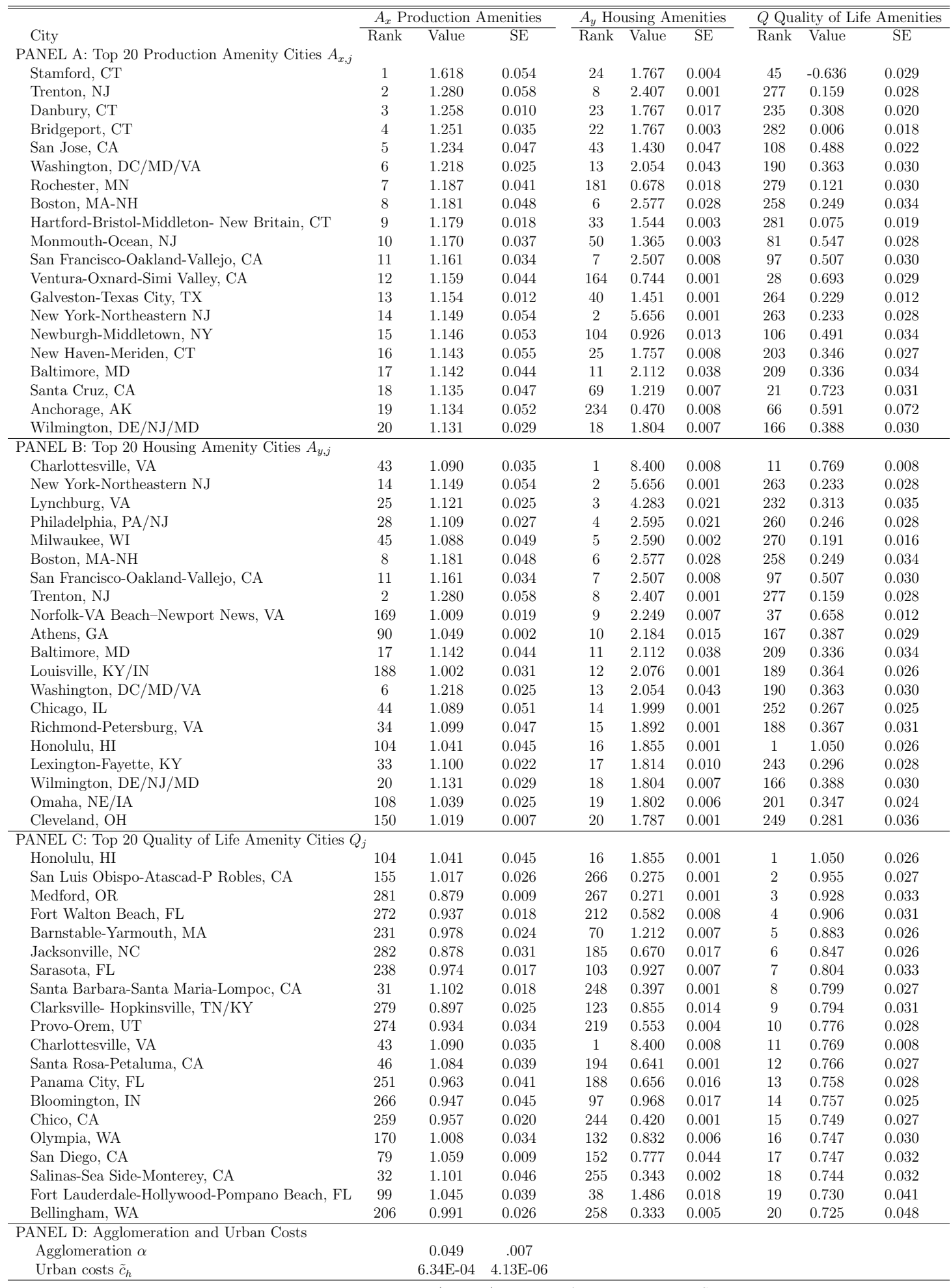

Notes: This table reports diagonally weighted minimum distance (DWMD) estimates of the amenity levels. Standard errors are calculated using the method proposed by Gary Chamberlain (1984) and are reported in parentheses. 


\section{Conclusion}

Economic growth depends on how people and production are concentrated within and distributed across cities. The model in this paper is developed to answer the key questions in dynamic urban growth. Should cities be allowed to restrict entry like an exclusive clubs? As mobility increases within a country what policies can be setup to provide the correct incentives for cities to regulate growth efficiently from a national, as opposed to local, perspective? What are the contemporary production and quality of life amenity levels within cities controlling for historic agglomerations that are based on production technologies such as portages across rapids?

Surprisingly, this paper finds that zoning laws setup by revenue maximizing governments produce the efficient level of barriers to migration for population to be distributed efficiently across the entire system of cities. Further, these barriers provide incentives for individuals to create the efficient set of cities when cities are heterogeneous in both production and quality of life amenities. Systems of cities with excess mobility are found to over value production amenities and systems of cities with excess restrictions over value quality of life amenities. These results extend the static economic intuition, from Pigou (1920) and Knight (1924) about when markets are efficient, to a dynamic context where the set of cities is endogenous.

This model provides a framework for further research on the extensive margin of city formation. For example, the model is built using homogeneous agents but could be extended to heterogeneous agents. In addition, this paper (and most migration models) focus on wages and cost of living as the sole determinants of migration. However, this model could be extended to allow the proximity of individuals to different cities both geographically and in preference-space to enter the model. Geographic proximity can be an important factor in structuring migration patterns among cities. For instance, Chicago is a productive city which offers high wages and a reasonable cost of living. This should encourage in-migration from across the entire United States, but Chicago receives migrants disproportionately from the immediately adjacent states. This regionalism which is unaddressed in most models may have important ramifications for city creation and growth.

Finally, the amenity estimates suggest population growth may be subject to inefficient path dependence. The estimates suggest that the landscape for production amenities has changed since the time that many of these cities were created. With global climate change we should expect the landscape to continue to change, and perhaps at a greater pace. Further research is needed to better understand the optimal dynamic response to a changing 
landscape. For example, what is the efficient speed of re-optimization of population away from some cities and into others when the fixed capital in currently oversized cities is taken into account. 


\section{References}

Abdel-Rahman, H.M. and A. Anas, "Theories of systems of cities," Handbook of Regional and Urban Economics, 2004, 4, 2293-2339.

Albouy, D., "The unequal geographic burden of federal taxation," Journal of Political Economy, 2009, 117 (4), 635-667.

_ , "Evaluating the Efficiency and Equity of Federal Fiscal Equalization," Journal of Public Economics, 2012.

Albouy, David and Nathan Seegert, "Optimal city size and the private-social wedge," in "46th Annual AREUEA Conference Paper" 2011.

Alonso, W., Location and land use: toward a general theory of land rent, Vol. 204, Harvard University Press Cambridge, MA, 1964.

Anas, A., "On the birth and growth of cities: Laissez-faire and planning compared," Regional Science and Urban Economics, 1992, 22 (2), 243-258.

Arnott, R.J. and J.E. Stiglitz, "Aggregate land rents, expenditure on public goods, and optimal city size," The Quarterly Journal of Economics, 1979, 93 (4), 471-500.

Behrens, Kristian, Gilles Duranton, and Frédéric Robert-Nicoud, "Productive cities: Sorting, selection, and agglomeration," 2010.

Bleakley, Hoyt and Jeffrey Lin, "Portage and Path Dependence," The Quarterly Journal of Economics, 2012, p. qjs011.

Capozza, D.R. and R.W. Helsley, "The stochastic city," Journal of Urban Economics, 1990, 28 (2), 187-203.

Chamberlain, Gary, "Panel data," Handbook of econometrics, 1984, 2, 1247-1318.

Cuberes, D., "The rise and decline of cities," Texto para Discussão-Universidade de Chicago, Setembro de, 2004.

_, The rise and decline of cities, University of Chicago, Dept. of Economics, 2005.

Davies, Donald and David Weinstein, "Bones, Bombs, and Break Points: The Geography of Economic Activity," THE AMERICAN ECONOMIC REVIEW, 2002.

Desmet, Klaus and Esteban Rossi-Hansberg, "Urban Accounting and Welfare," The American Economic Review, 2013, 103 (6), 2296-2327.

Duranton, G. and D. Puga, "Micro-foundations of urban agglomeration economies," Handbook of regional and urban economics, 2004, 4, 2063-2117. 
Fujita, M., A. Anderson, and W. Isard, Spatial development planning: a dynamic convex programming approach, North-Holland, 1978.

Fujita, Masahisa and Jacques-François Thisse, Economics of Agglomeration: Cities, Industrial Location, and Globalization, Cambridge university press, 2013.

Gabriel, Stuart A and Stuart S Rosenthal, "Quality of the business environment versus quality of life: do firms and households like the same cities?," Review of Economics and Statistics, 2004, 86 (1), 438-444.

Glaeser, Edward L and Matthew E Kahn, "Sprawl and urban growth," Handbook of regional and urban economics, 2004, 4, 2481-2527.

Helsley, Robert W and William C Strange, "City formation with commitment," Regional Science and Urban Economics, 1994, 24 (3), 373-390.

Henderson, J.V., "Efficiency of resource usage and city size," Journal of Urban Economics, 1986, 19 (1), 47-70.

- and A.J. Venables, "The dynamics of city formation," Review of Economic Dynamics, 2009, 12 (2), 233-254.

- and Y.M. Ioannides, "Aspects of growth in a system of cities," Journal of Urban Economics, 1981, 10 (1), 117-139.

Ioannides, Y.M., "Temporal risks and the tenure decision in housing markets* 1," Economics letters, 1979, 4 (3), 293-297.

Knight, F.H., "Some fallacies in the interpretation of social cost," The Quarterly Journal of Economics, 1924, 38 (4), 582-606.

Krugman, Paul, "Urban concentration: the role of increasing returns and transport costs," International Regional Science Review, 1996, 19 (1-2), 5-30.

Mills, E.S., "An aggregative model of resource allocation in a metropolitan area," The American Economic Review, 1967, 57 (2), 197-210.

Murphy, Daniel, "Urban density and the substitution of market purchases for home production," University of Michigan, 2013.

Muth, Richard F, "Cities and housing; the spaital pattern of urban residential land use," 1969.

Pigou, Arthur C, "The economics of welfare," London, McMillan, 1920.

Rappaport, Jordan, "Consumption amenities and city population density," Regional Science and Urban Economics, 2008, 38 (6), 533-552. 
Roback, J., "Wages, rents, and the quality of life," The Journal of Political Economy, 1982, pp. $1257-1278$.

Rosen, Sherwin, "Wage-based indexes of urban quality of life," Current issues in urban economics, 1979, 3.

Rosenthal, S.S. and W.C. Strange, "Evidence on the nature and sources of agglomeration economies," Handbook of regional and urban economics, 2004, 4, 2119-2171.

Saiz, Albert, "The geographic determinants of housing supply," The Quarterly Journal of Economics, 2010, 125 (3), 1253-1296.

Salant, S. and N. Seegert, "Private Access Fees and Congestion: Is There a Role for Government After All?," 2014.

Seegert, N., "A Sequential Growth Model Of Cities With Rushes," 2011.

Tolley, G.S., "The welfare economics of city bigness," Journal of Urban Economics, 1974, 1 (3), 324-345.

Venables, A.J., "Spatial disparities in developing countries: cities, regions, and international trade," Journal of Economic Geography, 2005, 5 (1), 3. 


\section{Appendix A: Set of Cities Discussion}

This appendix briefly discusses the incentives for local governments and systems of cities with free mobility to create cities.

Individuals with free mobility continue to create cities to maximize the shared average benefit $\bar{b}$. As the number of cities increase the population in established cities weakly decreases causing the shared level of average benefit to weakly increase. Because individuals care only about the shared level of average benefit, they continue to produce cities until the next established city would be unstable, $\sum_{j}^{k} N_{j, k}<N$ and $\sum_{j}^{k+1} N_{j, k+1}>N$.

Despite the similar incentives as the central planner, individuals with free mobility may establish too few cities. To see this, consider the case where in equilibrium with free mobility the hinterland is empty, $\sum_{j}^{k_{2}}=1 N_{j, 2, k_{2}}=N$, and the last city has the population that maximizes its average benefit, $N_{k_{2}, 2}=\hat{N}_{k_{2}}$. Consider the population distribution if the central planner establishes the same number of cities, allocates the population to the last city that maximizes the average benefit, and enforces the mobility condition such that there may sub-optimally be remaining population in the hinterland. In this case, the shared level of average benefit and marginal benefit are equal but occur at different population levels for all cities other than city $k$ because for all stable populations the marginal benefit is less than or equal to the average benefit. This implies the efficient population in each city, determined by the central planner, is weakly less than the population determined by a system with free mobility. Therefore, in this scenario there is excess population in the hinterland that the central planner may be able to use to create additional cities.

With local governments, the population of established cities in an equilibrium with $k$ cities does not change if $k+1$ cities are created in equilibrium. In the first stage individuals sequentially establish cities such that the maximum average benefit of city $j$ is greater than or equal to the average benefit in city $j+1$. This implies the individual with the first decision in stage one will create the city with the largest maximum average benefit and set

the population limit $\hat{N}_{1}$. The next $\hat{N}_{1}$ mass of individuals will not establish a city since the average benefit in city 1 is greater or equal to the average benefit produced by city 2 in equilibrium. The next individual creates the second city as long as the maximum average benefit is greater than the benefit provided by the hinterland. The average benefit this individual receives in equilibrium is less than or equal to the benefit individuals in city 1 receive but the population limit excludes additional movement into city 1 . This pattern continues until $k$ cities have been established such that,

$$
\sum_{j}^{k} \hat{N}_{j}<N \quad \text { and } \quad \sum_{j}^{k+1} \hat{N}_{j}>N
$$

\section{Appendix B: Amenity Level Estimates}

This appendix reports the amenity level estimates for all 282 cities. Tables A.1 - A.5 report the amenity levels, the cities rank, and the standard errors where the cities are listed by alpha- 
betical order. The diagonally weighted minimum estimation method uses a weighting matrix $\operatorname{diag}\left(V^{-1}\right)$ where the matrix $V$ is the variance-covariance matrix of the moment conditions. In contrast, optimal minimum distance uses a weighting matrix of $V^{-1}$ and equally weighted minimum distance uses the identity matrix. The standard errors are calculated using the method proposed by Gary Chamberlain (1984) $\widehat{\operatorname{var}(\widehat{\Omega})}=\left(G^{\prime} A G\right)^{-1} G^{\prime} W V W G\left(G^{\prime} A G\right)^{-1}$, where $W$ is the weighting matrix $\operatorname{diag}\left(V^{-1}\right)$ and $G$ is the Jacobian matrix evaluated at the estimated parameters $\hat{\Omega}$. 
Table A.1: Amenity Level Estimates Part 1 A-C

\begin{tabular}{|c|c|c|c|c|c|c|c|c|c|}
\hline \multirow[b]{2}{*}{ City } & \multicolumn{3}{|c|}{ 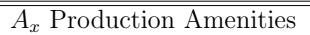 } & \multicolumn{3}{|c|}{$A_{y}$ Housing Amenities } & \multicolumn{3}{|c|}{$Q$ Quality of Life Amenities } \\
\hline & Rank & Value & $\mathrm{SE}$ & Rank & Value & SE & Rank & Value & $\mathrm{SE}$ \\
\hline Abilene, TX & 278 & 0.906 & 0.039 & 227 & 0.502 & 0.102 & 24 & 0.712 & 0.064 \\
\hline Akron, OH & 162 & 1.014 & 0.029 & 37 & 1.508 & 0.206 & 154 & 0.410 & 0.952 \\
\hline Albany, GA & 49 & 1.082 & 0.030 & 232 & 0.473 & 0.027 & 244 & 0.292 & 0.243 \\
\hline Albany-Schenectady-Troy, NY & 103 & 1.042 & 0.039 & 154 & 0.767 & 0.194 & 148 & 0.422 & 0.130 \\
\hline Albuquerque, NM & 159 & 1.015 & 0.038 & 144 & 0.795 & 0.239 & 141 & 0.433 & 0.183 \\
\hline Alexandria, LA & 96 & 1.046 & 0.027 & 250 & 0.383 & 0.087 & 245 & 0.292 & 0.037 \\
\hline Allentown-Bethlehem-Easton, PA/NJ & 121 & 1.032 & 0.023 & 64 & 1.248 & 0.019 & 115 & 0.473 & 0.193 \\
\hline Altoona, PA & 199 & 0.997 & 0.036 & 162 & 0.749 & 0.055 & 213 & 0.332 & 0.100 \\
\hline Amarillo, TX & 229 & 0.979 & 0.021 & 245 & 0.407 & 0.003 & 119 & 0.467 & 0.084 \\
\hline Anchorage, AK & 19 & 1.134 & 0.052 & 234 & 0.470 & 0.008 & 66 & 0.591 & 0.072 \\
\hline Ann Arbor, MI & 47 & 1.083 & 0.025 & 140 & 0.809 & 0.021 & 130 & 0.441 & 0.036 \\
\hline Anniston, AL & 132 & 1.026 & 0.026 & 189 & 0.650 & 0.060 & 257 & 0.252 & 0.331 \\
\hline Appleton-Oshkosh-Neenah, WI & 95 & 1.047 & 0.063 & 156 & 0.764 & 0.019 & 251 & 0.270 & 0.015 \\
\hline Asheville, $\mathrm{NC}$ & 218 & 0.985 & 0.030 & 117 & 0.868 & 0.008 & 77 & 0.555 & 0.034 \\
\hline Athens, GA & 90 & 1.049 & 0.002 & 10 & 2.184 & 0.015 & 167 & 0.387 & 0.029 \\
\hline Atlanta, GA & 68 & 1.065 & 0.048 & 54 & 1.330 & 0.047 & 200 & 0.349 & 0.053 \\
\hline Atlantic City, NJ & 38 & 1.094 & 0.038 & 100 & 0.937 & 0.010 & 89 & 0.521 & 0.031 \\
\hline Auburn-Opekika, AL & 201 & 0.996 & 0.036 & 175 & 0.706 & 0.014 & 90 & 0.520 & 0.031 \\
\hline Augusta-Aiken, GA-SC & 178 & 1.005 & 0.053 & 141 & 0.803 & 0.002 & 171 & 0.380 & 0.016 \\
\hline Austin, TX & 57 & 1.073 & 0.033 & 90 & 1.040 & 0.001 & 134 & 0.439 & 0.029 \\
\hline Bakersfield, CA & 72 & 1.063 & 0.034 & 271 & 0.247 & 0.002 & 172 & 0.378 & 0.017 \\
\hline Baltimore, MD & 17 & 1.142 & 0.044 & 11 & 2.112 & 0.038 & 209 & 0.336 & 0.034 \\
\hline Barnstable-Yarmouth, MA & 231 & 0.978 & 0.024 & 70 & 1.212 & 0.007 & 5 & 0.883 & 0.026 \\
\hline Baton Rouge, LA & 62 & 1.069 & 0.023 & 71 & 1.211 & 0.005 & 217 & 0.328 & 0.031 \\
\hline Beaumont-Port Arthur-Orange,TX & 42 & 1.090 & 0.045 & 207 & 0.611 & 0.016 & 273 & 0.175 & 0.020 \\
\hline Bellingham, WA & 206 & 0.991 & 0.026 & 258 & 0.333 & 0.005 & 20 & 0.725 & 0.048 \\
\hline Benton Harbor, MI & 256 & 0.958 & 0.040 & 149 & 0.785 & 0.015 & 129 & 0.445 & 0.026 \\
\hline Billings, MT & 193 & 0.999 & 0.015 & 274 & 0.241 & 0.006 & 147 & 0.423 & 0.022 \\
\hline Biloxi-Gulfport, MS & 97 & 1.046 & 0.044 & 193 & 0.641 & 0.011 & 94 & 0.509 & 0.036 \\
\hline Binghamton, NY & 258 & 0.957 & 0.046 & 196 & 0.640 & 0.003 & 113 & 0.475 & 0.011 \\
\hline Birmingham, AL & 82 & 1.057 & 0.040 & 136 & 0.819 & 0.002 & 233 & 0.309 & 0.005 \\
\hline Bloomington, IN & 266 & 0.947 & 0.045 & 97 & 0.968 & 0.017 & 14 & 0.757 & 0.025 \\
\hline Bloomington-Normal, IL & 65 & 1.067 & 0.056 & 233 & 0.471 & 0.006 & 236 & 0.307 & 0.023 \\
\hline Boise City, ID & 270 & 0.939 & 0.022 & 180 & 0.685 & 0.003 & 52 & 0.624 & 0.029 \\
\hline Boston, MA-NH & 8 & 1.181 & 0.048 & 6 & 2.577 & 0.028 & 258 & 0.249 & 0.034 \\
\hline Bremerton, WA & 66 & 1.067 & 0.025 & 58 & 1.304 & 0.003 & 60 & 0.606 & 0.036 \\
\hline Bridgeport, CT & 4 & 1.251 & 0.035 & 22 & 1.767 & 0.003 & 282 & 0.006 & 0.018 \\
\hline Brockton, MA & 41 & 1.091 & 0.038 & 44 & 1.418 & 0.008 & 156 & 0.407 & 0.018 \\
\hline Brownsville-Harlingen-San Benito, TX & 124 & 1.030 & 0.005 & 110 & 0.901 & 0.008 & 265 & 0.220 & 0.006 \\
\hline Bryan-College Station, TX & 36 & 1.098 & 0.023 & 122 & 0.855 & 0.013 & 205 & 0.342 & 0.030 \\
\hline Buffalo-Niagara Falls, NY & 167 & 1.012 & 0.041 & 89 & 1.055 & 0.002 & 248 & 0.284 & 0.006 \\
\hline Canton, $\mathrm{OH}$ & 214 & 0.987 & 0.016 & 74 & 1.203 & 0.006 & 192 & 0.360 & 0.003 \\
\hline Cedar Rapids, IA & 153 & 1.017 & 0.039 & 155 & 0.765 & 0.004 & 161 & 0.392 & 0.014 \\
\hline Champaign-Urbana-Rantoul, IL & 263 & 0.954 & 0.024 & 211 & 0.583 & 0.010 & 26 & 0.700 & 0.035 \\
\hline Charleston-N.Charleston,SC & 122 & 1.032 & 0.031 & 201 & 0.629 & 0.006 & 91 & 0.518 & 0.035 \\
\hline Charlotte-Gastonia-Rock Hill, NC-SC & 88 & 1.052 & 0.057 & 72 & 1.205 & 0.042 & 246 & 0.292 & 0.036 \\
\hline Charlottesville, VA & 43 & 1.090 & 0.035 & 1 & 8.400 & 0.008 & 11 & 0.769 & 0.008 \\
\hline Chattanooga, TN/GA & 145 & 1.021 & 0.013 & 82 & 1.140 & 0.015 & 178 & 0.374 & 0.032 \\
\hline Chicago, IL & 44 & 1.089 & 0.051 & 14 & 1.999 & 0.001 & 252 & 0.267 & 0.025 \\
\hline Chico, CA & 259 & 0.957 & 0.020 & 244 & 0.420 & 0.001 & 15 & 0.749 & 0.027 \\
\hline Cincinnati-Hamilton, OH/KY/IN & 89 & 1.050 & 0.035 & 41 & 1.448 & 0.020 & 261 & 0.238 & 0.034 \\
\hline Clarksville- Hopkinsville, TN/KY & 279 & 0.897 & 0.025 & 123 & 0.855 & 0.014 & 9 & 0.794 & 0.031 \\
\hline Cleveland, $\mathrm{OH}$ & 150 & 1.019 & 0.007 & 20 & 1.787 & 0.001 & 249 & 0.281 & 0.036 \\
\hline Colorado Springs, CO & 252 & 0.962 & 0.029 & 214 & 0.581 & 0.002 & 30 & 0.688 & 0.012 \\
\hline Columbia, MO & 276 & 0.912 & 0.032 & 177 & 0.694 & 0.004 & 27 & 0.700 & 0.041 \\
\hline Columbia, SC & 186 & 1.002 & 0.031 & 142 & 0.800 & 0.003 & 107 & 0.490 & 0.035 \\
\hline Columbus, GA/AL & 173 & 1.007 & 0.026 & 21 & 1.781 & 0.004 & 122 & 0.461 & 0.018 \\
\hline Columbus, $\mathrm{OH}$ & 112 & 1.035 & 0.025 & 27 & 1.653 & 0.046 & 222 & 0.323 & 0.031 \\
\hline Corpus Christi, TX & 76 & 1.060 & 0.029 & 243 & 0.435 & 0.004 & 116 & 0.472 & 0.039 \\
\hline
\end{tabular}

Notes: This table reports diagonally weighted minimum distance (DWMD) estimates of the amenity levels. Standard errors are calculated using the method proposed by Gary Chamberlain (1984) and are reported in parentheses. 
Table A.2: Amenity Level Estimates Part 2 D-I

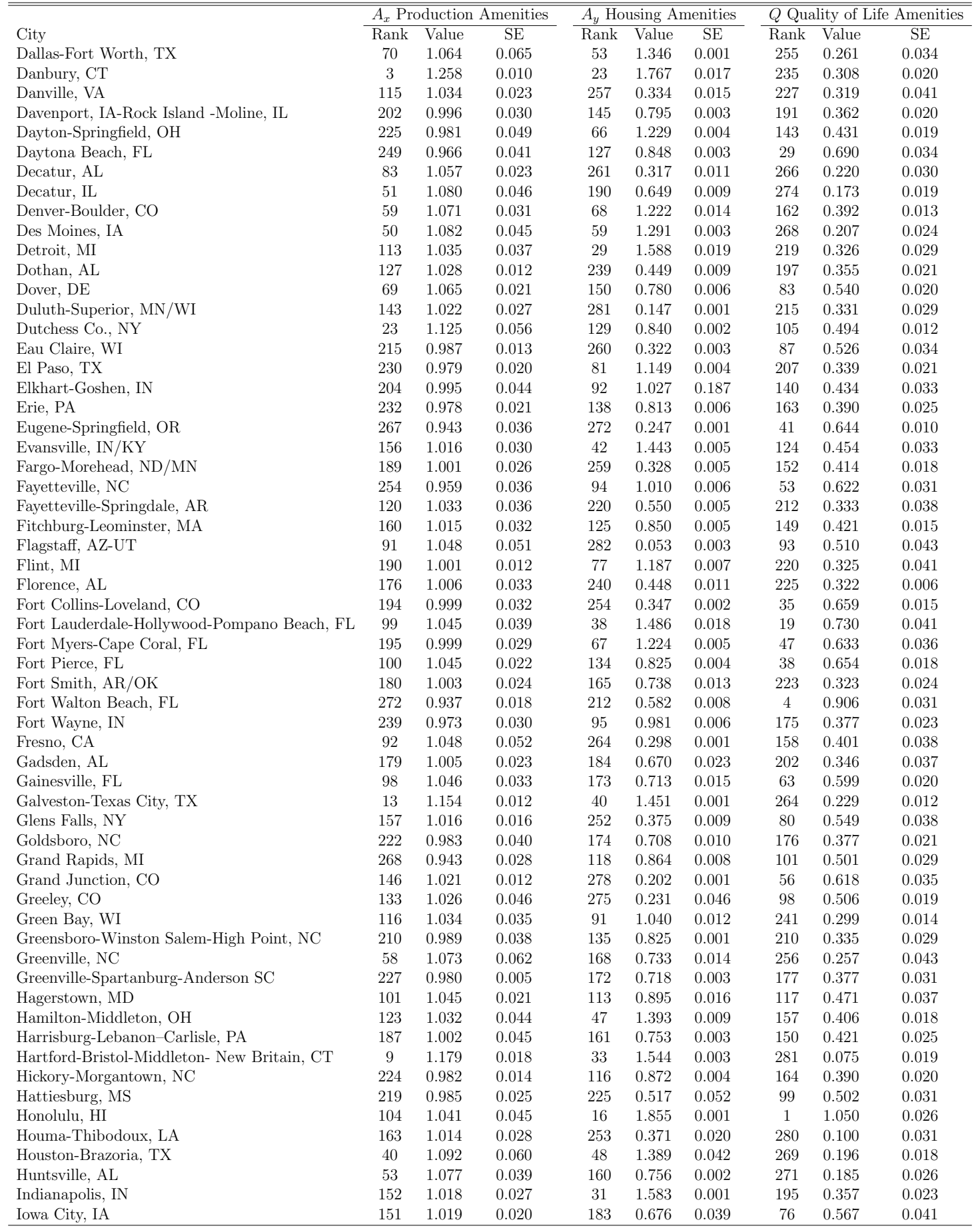

Notes: This table reports diagonally weighted minimum distance (DWMD) estimates of the amenity levels. Standard errors are calculated using the method proposed by Gary Chamberlain (1984) and are reported in parentheses. 
Table A.3: Amenity Level Estimates Part 3 J-M

\begin{tabular}{|c|c|c|c|c|c|c|c|c|c|}
\hline \multirow[b]{2}{*}{ City } & \multicolumn{3}{|c|}{$\bar{c}_{A_{x}}$ Production Amenities } & \multicolumn{3}{|c|}{ 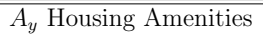 } & \multicolumn{3}{|c|}{$Q$ Q Quality of Life Amenities } \\
\hline & Rank & Value & $\mathrm{SE}$ & Rank & Value & SE & Rank & Value & SE \\
\hline Jackson, MI & 235 & 0.975 & 0.040 & 182 & 0.677 & 0.007 & 86 & 0.527 & 0.023 \\
\hline Jackson, MS & 128 & 1.028 & 0.022 & 226 & 0.506 & 0.005 & 186 & 0.367 & 0.027 \\
\hline Jacksonville, FL & 164 & 1.014 & 0.025 & 87 & 1.063 & 0.030 & 82 & 0.544 & 0.008 \\
\hline Jacksonville, NC & 282 & 0.878 & 0.031 & 185 & 0.670 & 0.017 & 6 & 0.847 & 0.026 \\
\hline Jamestown-Dunkirk, NY & 280 & 0.888 & 0.031 & 238 & 0.456 & 0.019 & 43 & 0.642 & 0.022 \\
\hline Johnson City-Kingsport-Bristol, TN/VA & 245 & 0.968 & 0.042 & 121 & 0.860 & 0.013 & 196 & 0.356 & 0.031 \\
\hline Johnstown, PA & 260 & 0.957 & 0.024 & 230 & 0.480 & 0.014 & 234 & 0.309 & 0.024 \\
\hline Joplin, MO & 261 & 0.955 & 0.046 & 203 & 0.622 & 0.046 & 110 & 0.479 & 0.030 \\
\hline Kalamazoo-Portage, MI & 242 & 0.970 & 0.043 & 158 & 0.759 & 0.011 & 126 & 0.453 & 0.035 \\
\hline Kankakee, IL & 140 & 1.023 & 0.053 & 210 & 0.586 & 0.297 & 123 & 0.455 & 0.028 \\
\hline Kansas City, MO-KS & 109 & 1.038 & 0.047 & 79 & 1.175 & 0.001 & 226 & 0.321 & 0.015 \\
\hline LaCrosse, WI & 134 & 1.026 & 0.021 & 143 & 0.797 & 0.021 & 168 & 0.387 & 0.026 \\
\hline Lafayette, LA & 26 & 1.111 & 0.022 & 55 & 1.309 & 0.005 & 278 & 0.131 & 0.031 \\
\hline Lafayette-W. Lafayette, IN & 158 & 1.016 & 0.031 & 107 & 0.907 & 0.010 & 114 & 0.474 & 0.032 \\
\hline Lake Charles, LA & 78 & 1.059 & 0.030 & 222 & 0.544 & 0.005 & 267 & 0.219 & 0.031 \\
\hline Lakeland-Winterhaven, FL & 240 & 0.973 & 0.032 & 191 & 0.648 & 0.004 & 54 & 0.622 & 0.027 \\
\hline Lancaster, PA & 207 & 0.991 & 0.060 & 96 & 0.976 & 0.006 & 71 & 0.574 & 0.041 \\
\hline Lansing-E. Lansing, MI & 220 & 0.984 & 0.029 & 124 & 0.852 & 0.016 & 111 & 0.478 & 0.011 \\
\hline Laredo, TX & 137 & 1.025 & 0.006 & 270 & 0.261 & 0.003 & 208 & 0.339 & 0.028 \\
\hline Las Vegas, NV & 102 & 1.044 & 0.034 & 249 & 0.385 & 0.002 & 61 & 0.602 & 0.039 \\
\hline Lexington-Fayette, KY & 33 & 1.100 & 0.022 & 17 & 1.814 & 0.010 & 243 & 0.296 & 0.028 \\
\hline Lima, OH & 216 & 0.987 & 0.010 & 131 & 0.837 & 1.070 & 125 & 0.454 & 0.033 \\
\hline Madison, WI & 63 & 1.069 & 0.040 & 146 & 0.792 & 0.008 & 135 & 0.438 & 0.033 \\
\hline Manchester, NH & 135 & 1.026 & 0.012 & 108 & 0.906 & 0.006 & 84 & 0.537 & 0.012 \\
\hline Mansfield, OH & 237 & 0.975 & 0.048 & 153 & 0.775 & 0.010 & 139 & 0.436 & 0.027 \\
\hline McAllen-Edinburg-Pharr-Mission, TX & 136 & 1.026 & 0.022 & 139 & 0.813 & 0.005 & 275 & 0.172 & 0.031 \\
\hline Medford, OR & 281 & 0.879 & 0.009 & 267 & 0.271 & 0.001 & 3 & 0.928 & 0.033 \\
\hline Melbourne-Titusville-Cocoa-Palm Bay, FL & 221 & 0.984 & 0.018 & 99 & 0.945 & 0.001 & 39 & 0.654 & 0.025 \\
\hline Memphis, TN/AR/MS & 75 & 1.061 & 0.035 & 52 & 1.350 & 0.002 & 239 & 0.303 & 0.030 \\
\hline Merced, CA & 61 & 1.070 & 0.030 & 247 & 0.400 & 0.027 & 187 & 0.367 & 0.030 \\
\hline Miami-Hialeah, FL & 168 & 1.010 & 0.023 & 62 & 1.267 & 0.026 & 33 & 0.664 & 0.025 \\
\hline Milwaukee, WI & 45 & 1.088 & 0.049 & 5 & 2.590 & 0.002 & 270 & 0.191 & 0.016 \\
\hline Minneapolis-St. Paul, MN & 64 & 1.068 & 0.010 & 36 & 1.513 & 0.026 & 224 & 0.323 & 0.034 \\
\hline Mobile, AL & 208 & 0.991 & 0.030 & 221 & 0.550 & 0.001 & 112 & 0.478 & 0.029 \\
\hline Modesto, CA & 93 & 1.048 & 0.050 & 179 & 0.688 & 0.040 & 70 & 0.575 & 0.026 \\
\hline Monmouth-Ocean, NJ & 10 & 1.170 & 0.037 & 50 & 1.365 & 0.003 & 81 & 0.547 & 0.028 \\
\hline Monroe, LA & 154 & 1.017 & 0.023 & 166 & 0.736 & 0.056 & 214 & 0.332 & 0.027 \\
\hline Montgomery, AL & 191 & 1.001 & 0.032 & 204 & 0.616 & 0.009 & 104 & 0.495 & 0.030 \\
\hline Muncie, IN & 212 & 0.988 & 0.020 & 111 & 0.898 & 0.015 & 146 & 0.424 & 0.034 \\
\hline Myrtle Beach, SC & 255 & 0.959 & 0.020 & 205 & 0.612 & 0.013 & 46 & 0.634 & 0.022 \\
\hline
\end{tabular}

Notes: This table reports diagonally weighted minimum distance (DWMD) estimates of the amenity levels. Standard errors are calculated using the method proposed by Gary Chamberlain (1984) and are reported in parentheses. 
Table A.4: Amenity Level Estimates Part 4 N-S

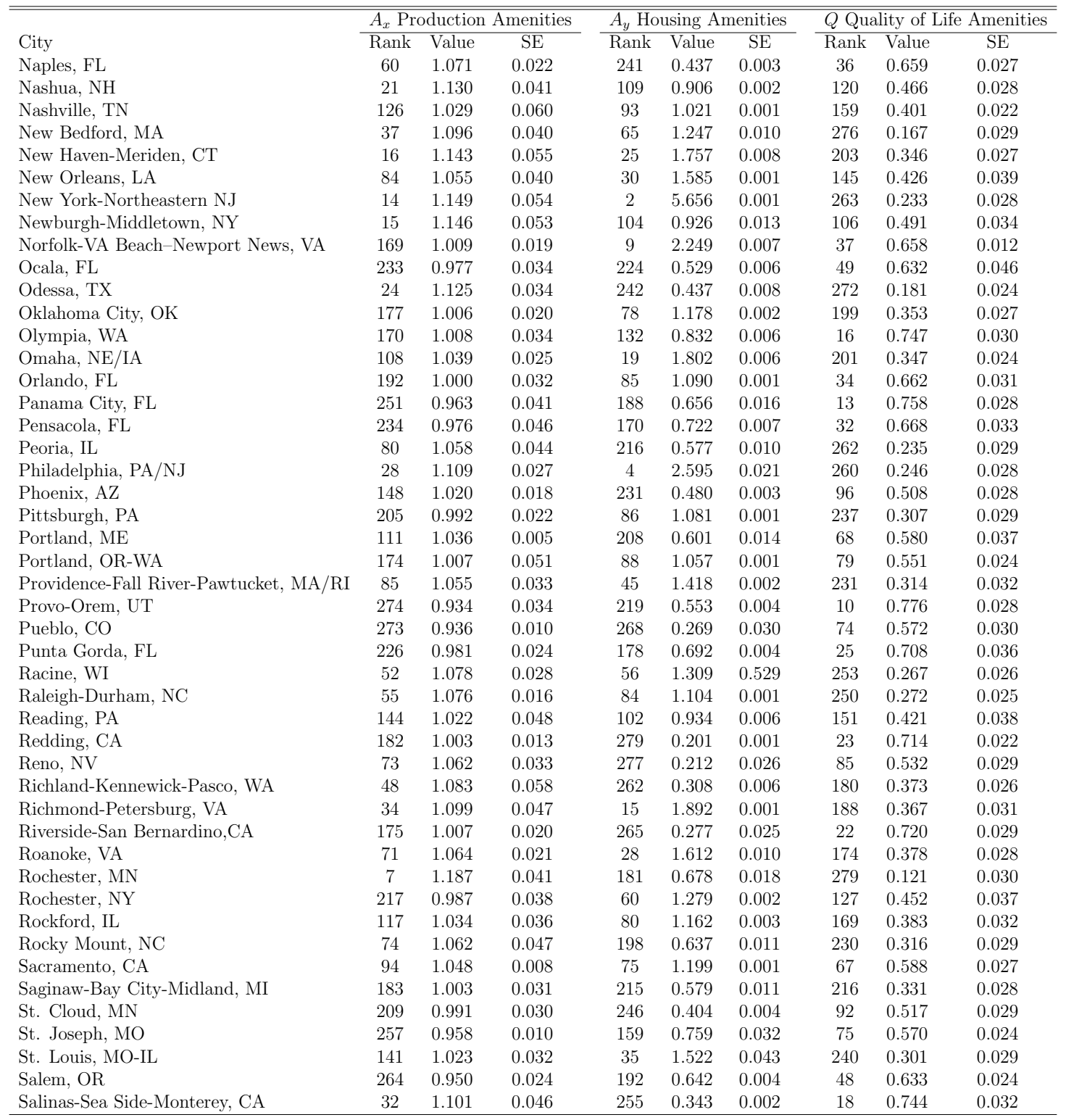

Notes: This table reports diagonally weighted minimum distance (DWMD) estimates of the amenity levels. Standard errors are calculated using the method proposed by Gary Chamberlain (1984) and are reported in parentheses. 
Table A.5: Amenity Level Estimates Part 5 S-Z

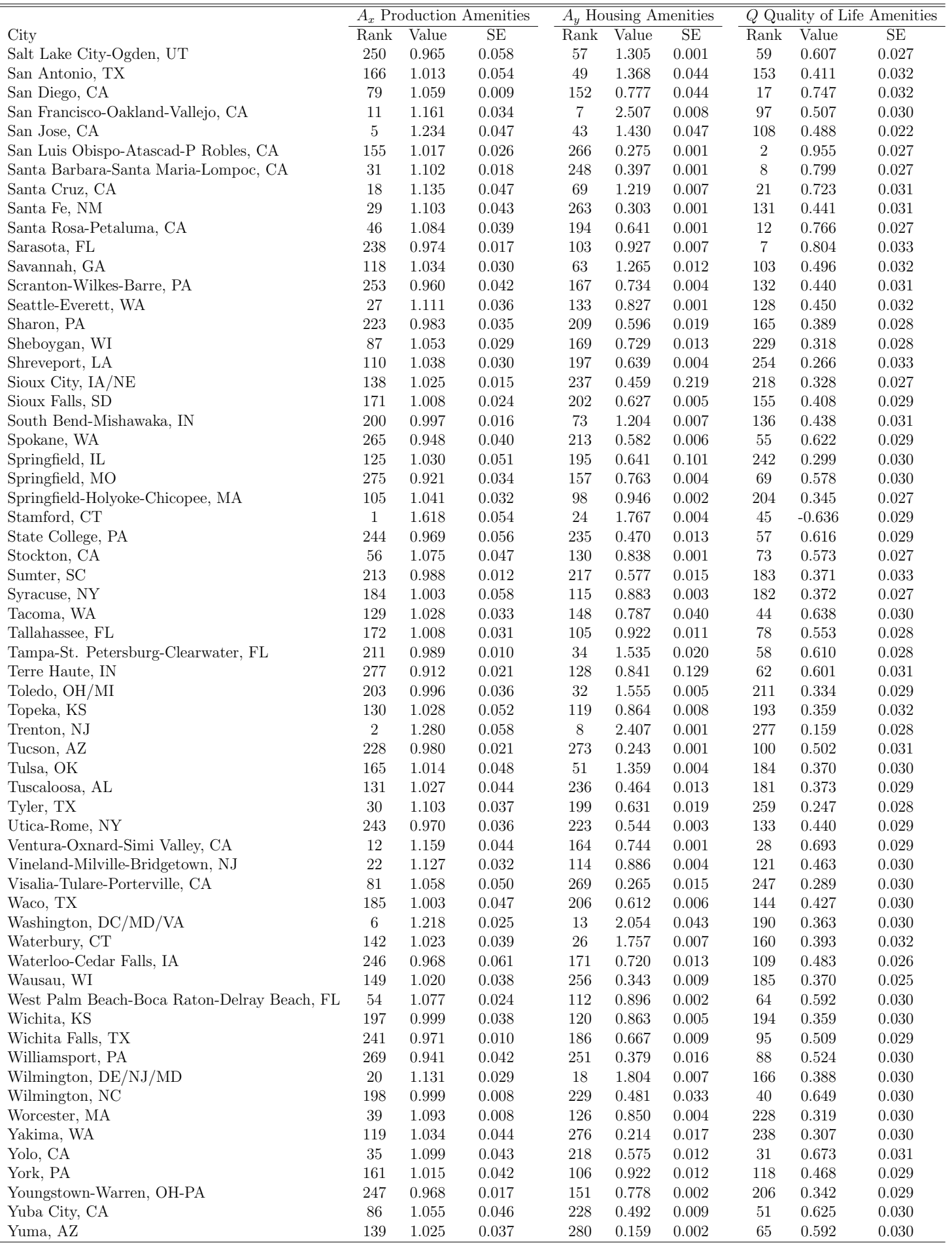

Notes: This table reports diagonally weighted minimum distance (DWMD) estimates of the amenity levels. Standard errors are calculated using the method proposed by Gary Chamberlain (1984) and are reported in parentheses. 